Article

\title{
Biomarkers of Progression after HIV Acute/Early Infection: Nothing Compares to $\mathrm{CD}^{+} \mathrm{T}$-cell Count?
}

\author{
Gabriela Turk ${ }^{1, *}$ (D), Yanina Ghiglione ${ }^{1}$, Macarena Hormanstorfer ${ }^{2}$, Natalia Laufer 1,3 (D), \\ Romina Coloccini ${ }^{1}$, Jimena Salido ${ }^{1}$, César Trifone ${ }^{1}$, María Julia Ruiz ${ }^{1}$, Juliana Falivene ${ }^{1}$, \\ María Pía Holgado ${ }^{1}$ (D), María Paula Caruso ${ }^{1}$, María Inés Figueroa ${ }^{2,3}$, Horacio Salomón ${ }^{1}$, \\ Luis D. Giavedoni ${ }^{4}$, María de los Ángeles Pando ${ }^{1}$, María Magdalena Gherardi ${ }^{1}$, \\ Roberto Daniel Rabinovich ${ }^{1}$, Pedro A. Pury ${ }^{5}$ (i) and Omar Sued ${ }^{2}$ \\ 1 CONICET-Universidad de Buenos Aires, Instituto de Investigaciones Biomédicas en Retrovirus y \\ SIDA (INBIRS), Universidad de Buenos Aires- CONICET, Paraguay 2155 Piso 11, Buenos Aires C1121ABG, \\ Argentina; yghiglione@fmed.uba.ar (Y.G.); nlaufer@fmed.uba.ar (N.L.); romina.coloccini@gmail.com (R.C.); \\ jimenasalido@gmail.com (J.S.); trifonecesar@gmail.com (C.T.); mariajulia83@gmail.com (M.J.R.); \\ juliana.falivene@gmail.com (J.F.); piaholgado@gmail.com (M.P.H.); pau_caruso@hotmail.com (M.P.C.); \\ hsalomon@fmed.uba.ar (H.S.); mpando@fmed.uba.ar (M.d.1.A.P.); mgherardi@fmed.uba.ar (M.M.G.); \\ rabinovichra@yahoo.com.ar (R.D.R.) \\ 2 Fundación Huésped, Buenos Aires C1202ABB, Argentina; hormanstorferm@gmail.com (M.H.); \\ maria.figueroa@huesped.org.ar (M.I.F.); omar.sued@huesped.org.ar (O.S.) \\ 3 Hospital Juan A. Fernández, Unidad Enfermedades Infecciosas, Buenos Aires C1425AGP, Argentina \\ 4 Southwest National Primate Research Center, Texas Biomedical Research Institute, San Antonio, TX 78227, \\ USA; lgiavedoni@txbiomed.org \\ 5 Facultad de Matemática, Astronomía, Física y Computación, Universidad Nacional de Córdoba, Córdoba \\ X5000HUA, Argentina; pury@famaf.unc.edu.ar \\ * Correspondence: gturk@fmed.uba.ar; Tel.: +54-11-4508-3689 (ext. 130)
}

Received: 12 December 2017; Accepted: 12 January 2018; Published: 13 January 2018

\begin{abstract}
Progression of HIV infection is variable among individuals, and definition disease progression biomarkers is still needed. Here, we aimed to categorize the predictive potential of several variables using feature selection methods and decision trees. A total of seventy-five treatment-naïve subjects were enrolled during acute/early HIV infection. CD4 ${ }^{+}$T-cell counts (CD4TC) and viral load $(\mathrm{VL})$ levels were determined at enrollment and for one year. Immune activation, HIV-specific immune response, Human Leukocyte Antigen (HLA) and C-C chemokine receptor type 5 (CCR5) genotypes, and plasma levels of 39 cytokines were determined. Data were analyzed by machine learning and non-parametric methods. Variable hierarchization was performed by Weka correlation-based feature selection and J48 decision tree. Plasma interleukin (IL)-10, interferon gamma-induced protein (IP)-10, soluble IL-2 receptor alpha (sIL-2R $\alpha$ ) and tumor necrosis factor alpha (TNF- $\alpha$ ) levels correlated directly with baseline VL, whereas IL-2, TNF- $\alpha$, fibroblast growth factor (FGF)-2 and macrophage inflammatory protein (MIP)- $1 \beta$ correlated directly with CD4 ${ }^{+}$T-cell activation $(p<0.05)$. However, none of these cytokines had good predictive values to distinguish "progressors" from "non-progressors". Similarly, immune activation, HIV-specific immune responses and HLA/CCR5 genotypes had low discrimination power. Baseline CD4TC was the most potent discerning variable with a cut-off of 438 cells $/ \mu \mathrm{L}$ (accuracy $=0.93, \mathrm{k}$-Cohen $=0.85$ ). Limited discerning power of the other factors might be related to frequency, variability and/or sampling time. Future studies based on decision trees to identify biomarkers of post-treatment control are warrantied.
\end{abstract}

Keywords: HIV; biomarkers; acute infection; disease progression; decision trees; soluble plasma factors; HLA; immune responses 


\section{Introduction}

Human Immunodeficiency Virus (HIV) infection causes an irreversible deterioration of the immune system ultimately leading to the development of AIDS in the vast majority of infected persons. Following virus transmission, acute/early phase of infection is characterized by a high-level peak of viremia, rapid loss of CD4 ${ }^{+}$T-cells in both peripheral blood and mucosal lymphoid tissues, and, in some cases, clinical symptoms [1,2]. Emergence of HIV-specific CD8 ${ }^{+}$T-cell response is associated with the drop of plasma viremia to a stable level; known as the viral set-point [3]. Within this general framework, it is also known that the rate of disease progression after acquiring the infection is very variable among individuals, allowing the identification of different subgroups: rapid progressors, typical progressors, viremic controllers or elite controllers [4].

The application of biomarkers in the diagnosis and management of cardiovascular diseases, several infections, immune and genetic disorders, as well as cancer is well known [5]. However, finding a reliable biomarker able to predict the rate of disease progression after acute/early HIV infection remains an important challenge. Nowadays, the HIV treatment guidelines recommended by the United States, the World Health Organization, the International AIDS Society and the European AIDS Clinical Society, adhere to providing universal combined antiretroviral treatment (cART) regardless of the infected persons were undergoing recent or chronic infection [6-9]. This might diminish the interest in finding a biomarker of disease progression. However, it should be considered that the application of biomarkers is beyond disease prediction and monitoring. Identifying biomarkers helps dissect the mechanisms underlying pathogenic processes and also plays an important role in drug discovery/design, development and validation [10]. On the other hand, differential public health approaches are necessary to maximize the use of constrained resources in low and middle-low income countries. Finally, even though the guidelines state that therapy should be initiated soon after diagnosis, they are not set in stone. Decisions must still be made on a case-by-case basis and the need to defer cART because of the presence of clinical and/or psychosocial factors. Therefore, biomarkers may aid in the medical decision for these particular cases. Thus, HIV biomarker is a field that still deserves continuous research to fill in the gaps in different aspects of HIV pathogenesis, discover new targets, improve current HIV treatment strategies, and aid in cure research.

Thus far, $\mathrm{CD}^{+}$T-cell counts and plasma viral load (VL) levels have remained the strongest correlates of progression and are the two markers routinely used in the clinical setting to monitor the infection [1]. In addition, other parameters such as levels of cell-associated viral DNA [11,12], immune activation and inflammation [13,14], several cytokines [15-18], HIV-specific immune responses [19-25], and genetic variants (recently reviewed in [26]) have been shown to be associated with disease progression and proposed as potential biomarkers. However, different limitations preclude them from being installed into the routine practice.

In 2008, an ongoing multicenter Argentine observational cohort of subjects diagnosed during primary HIV infection, named Grupo Argentino de Seroconversión study group, was created in Argentina. The aim of this consortium is to gather epidemiological, clinical, immunological and virological data of the individuals enrolled to dissect variables associated with different rates of disease progression soon after infection, and ultimately to identify potential markers associated with progression [27]. In an initial study based only on clinical variables, baseline VL > 100,000 copies/mL was associated with progression [27]. Later, in this cohort, it was demonstrated that CD8 ${ }^{+} \mathrm{T}$-cell specificity (higher proportion of early anti-Group-specific antigen (Gag) T-cells), functionality (enhanced viral inhibitory activity) and phenotype (preserved differentiation and lower proportion of exhausted cells) correlated with delayed disease progression [28,29]. Moreover, disease progression, in terms of viral load, could be correlated with a genetic score built based on Human Leukocyte Antigen (HLA) and C-C chemokine receptor type 5 (CCR5) genotypes genotypes [30]. Finally, it could be demonstrated that higher baseline T helper 17 (Th17) cell percentages were associated with lower baseline levels of immune T-cell activation and to lower rates of disease progression [31]. 
In this study, we took advantage of all these variables comprehensively studied in our cohort and that have been individually associated with disease progression and aimed to categorize their predictive potential. The complete set included 88 variables ( 16 clinical variables, 10 immunological variables, 10 genetic variables and 52 variables related to soluble plasma factors) measured in up to 75 individuals. Due to the large number of variables analyzed, we first ranked sets of different variables based on their correlations with each class of progression. Then, using the top ranked variables, we studied their predictive power by constructing decision trees. This machine learning approach generates a hierarchy of variables automatically and provides a quantitative measure of the predictive capability of a given set. Moreover, the decision trees automatically provide the best cut-off values for continuous variables and they are reliable classifiers.

\section{Materials and Methods}

\subsection{Study Subjects}

Seventy-five subjects with ongoing acute/early primary HIV infection (PHI) were enrolled by the Grupo Argentino de Seroconversión study group [27], an ongoing multicenter Argentine observational cohort of subjects diagnosed during primary HIV infection. Inclusion criteria for enrolment in the cohort are: age $>16$ years at first evaluation, confirmed diagnosis of primary HIV infection, and first (baseline) medical and laboratory evaluation (i.e., CD4 cell count and plasma HIV RNA) within six months of the probable date of infection. Primary HIV infection is defined as: (1) detection of HIV RNA or p24 antigen with a simultaneous negative or indeterminate Western blot assay; or (2) positive Western blot with a negative diagnostic within the previous six months. Hence, it includes subjects up to Fiebig VI. Data included in this study were obtained from enrolled subjects while they were off-ART. Samples and data obtained after ART initiation were not considered in the analysis. Of note, most subjects were enrolled between years 2008 and 2012, before international [32] and national [33] treatment guidelines recommended that all HIV-infected subjects should initiate ART immediately after diagnosis. Additionally, samples from $21 \mathrm{HIV-seronegative} \mathrm{healthy} \mathrm{donors} \mathrm{(HD)} \mathrm{were} \mathrm{obtained}$ from voluntary blood donors at the Sanatorio Dr Julio Mendez blood bank (Buenos Aires, Argentina). All donors were between 18 and 65 years old; completed and passed a survey on blood donation; and were screened for serological markers of HIV, Hepatitis C virus, Hepatitis B virus, Human T- cell lymphotropic virus I and II, Syphilis, Chagas disease, and Brucellosis before being accepted as donors.

\subsection{Ethical Considerations}

This study was reviewed and approved by two institutional review boards (IRB): Comité de Ética Humana, Facultad de Medicina, Universidad de Buenos Aires (11/11/2010 ExpUBA35.366/2010 Res CD 2815/2010) and Comité de Bioética, Fundación Huésped (18/05/2009, Buenos Aires, Argentina). Both HIV-infected participants and healthy donors provided written informed consents accepting to participate in this study.

\subsection{Samples}

Blood samples were collected from study participants at enrollment (baseline sample) and at 6 and 12 months post-presumed date of infection. Whole blood was centrifuged to separate plasma and stored at $-80^{\circ} \mathrm{C}$ until use. Peripheral blood mononuclear cells (PBMCs) were isolated by Ficoll-Hypaque density gradient centrifugation (GE Healthcare, Little Chalfont, UK) and cryopreserved for subsequent functional assays.

\subsection{HIV-1 Viral Load, CD4 ${ }^{+}$T-cell Count and Immune Activation}

Plasma VL was determined by branched-DNA assay (bDNA, Versant HIV-1 RNA 3.0 assay, Siemmens Healthcare, Erlangen, Germany). $\mathrm{CD} 4^{+} \mathrm{T}$-cell count was determined by flow cytometry double platform (BD FACSCanto, BD Biosciences, San Jose, CA, USA). CD4 ${ }^{+}$and CD8 ${ }^{+}$lymphocyte 
activation was analyzed on thawed and over-night rested PBMCs by flow cytometry. Cells were stained for $30 \mathrm{~min}$ at $4{ }^{\circ} \mathrm{C}$ with LIVE/DEAD Fixable NEAR-IR (Life Technologies, Carlsbad, CA, USA) to exclude dead cells, and with the following fluorochrome-conjugated antibodies (all of them from BD Biosciences, San Jose, CA, USA): anti-HLA- antigen D Related (DR)- Fluorescein isothiocyanate (FITC), anti-CD4-Peridinin Chlorophyll Protein Complex (PerCP), anti-CD38- Allophycocyanin (APC), anti-CD3-Phycoerythrin-Cyanin7 (PeCy7) and anti-CD8-Phycoerythrin (PE). Cells were acquired in a BD FACSCanto flow cytometer. Data acquisition and analysis was performed using the BD FACSDiva v8.0.1 software (BD Biosciences, San Jose, CA, USA). Initial gating was performed on living lymphocytes followed by gating on $\mathrm{CD}^{+} \mathrm{CD}^{+}$or $\mathrm{CD} 3^{+} \mathrm{CD} 8^{+}$events. Isotype-matched FITC- and APC-conjugated non-specific antibodies were used in each sample to accurately set HLA-DR and CD38 negative populations.

\subsection{Human Leukocyte Antigen (HLA) and CCR5 Genotyping}

HLA class I A and B typing was performed using an in-house protocol consisting in PCR amplification, nucleotide sequencing with nested primers and web-based sequence interpretation. CCR5- $\triangle 32$ deletion was identified by differences in PCR product size. Single Nucleotide Polymorphisms (SNPs) of the CCR5 gene corresponding to positions 29, 208, 627, 630, 676 and 927 were determined with Site Directed Mutagenesis-PCR-Restriction Fragment Length Polymorphism (SDM-PCR-RFLP) assay. All procedures were previously described in Coloccini et al. [30].

\subsection{HIV-Specific Cellular Immune Responses}

The magnitude and specificity of the HIV-specific cellular immune response were screened by interferon (IFN)- $\gamma$ Enzyme-Linked ImmunoSpot Assay (ELISPOT) in baseline samples as described previously [28,34].

\subsection{Quantitation of Soluble Plasma Factors}

Simultaneous determination of the following 39 cytokines and chemokines was performed using Luminex technology (MILLIPLEX MAP Human Cytokine/Chemokine, Merck Millipore, Billerica, MA, USA) in baseline samples: Endothelial growth factor (EGF), Eotaxin, fibroblast growth factor (FGF)-2, Fms-like tyrosine kinase (Flt)-3 Ligand, Fractalkine, granulocyte colony-stimulating factor (G-CSF), granulocyte-monocyte (GM)-CSF, GRO, IFN- $\alpha 2$, IFN- $\gamma$, interleukin (IL)- $1 \alpha$, IL-1 $\beta$, IL-1r $\alpha$, IL-2, IL-3, IL-4, IL-5, IL-6, IL-7, IL-8, IL-9, IL-10, IL-12 (p40), IL-12 (p70), IL-13, IL-15, IL-17, interferon gamma-induced protein (IP)-10, monocyte chemoattractant protein (MCP)-1, MCP-3, macrophage derived chemokine (MDC) (C-C motif chemokine (CCL)22), macrophage inflammatory protein (MIP)-1 $\alpha$, MIP-1 $\beta$, soluble CD40 ligand (sCD40L), soluble IL 2 receptor alpha (sIL-2R $\alpha$ ), tumor growth factor (TGF)- $\alpha$, tumor necrosis factor (TNF)- $\alpha$, TNF- $\beta$, and vascular endothelial growth factor (VEGF). Samples were processed and analyzed as described elsewhere [35]. Plasma lipopolysaccharide (LPS) quantitation was performed using the Limulus Amebocyte Lysate (LAL) assay (QCL-1000, Lonza, Walkersville, MD, USA).

\subsection{Definitions and Data Analysis}

The presumed date of infection was estimated as 14 days before the onset of symptoms or, in asymptomatic subjects, as the midpoint between the last negative and the first positive test or one month before the date of the indeterminate or negative Western blot assay [27]. Three dichotomic classes were constructed to segregate subjects according to their rate of disease progression over the first year postinfection or their capacity to control viral replication: $\mathrm{C} 1$ (defined on immunological criteria), C2 and C3 (defined on virological criteria). In C1, subjects were segregated according to whether their $\mathrm{CD} 4^{+} \mathrm{T}$-cell count dropped below 350 cells $/ \mu \mathrm{L}$ at any time during the first year postinfection ("progressors"), or not ("non-progressors") [27-29,31,36]. The 350 cells/ $\mu$ L-endpoint was chosen based on the national and international recommendations for HAART initiation by the year 2010, 
when most of these individuals were already enrolled. C2 segregated subjects according to whether they had $>100,000$ baseline HIV RNA copies/mL plasma or not, based on previous observations from the same cohort [27]. Similarly, C3 segregated subjects according to whether they had $>100,000 \mathrm{HIV}$ RNA copies/mL plasma or not at the 6-month sample (Figure 1A). The CD4 slope was calculated for each subject as the slope of the best-fit line obtained by linear regression of $\mathrm{CD} 4^{+} \mathrm{T}$-cell counts during the first year of infection and was represented as the $\mathrm{CD} 4^{+} \mathrm{T}$-cell count change per day (cells/ $\mu \mathrm{L} /$ day). Additive scores were created for each subject to compile host genetic information, as previously described by our group [30]. Similarly, scores based on cytokine data were created. Construction of genetic and cytokine-based scores is described in Appendix A, where all variables evaluated in this study are defined. For certain analyses, the whole database was subdivided in three self-including parts, i.e., the small database $(N=27)$, the intermediate database $(N=48)$ and the whole database $(N=75)$ (Figure 1B).

Statistical analyses were performed using GraphPad Prism 7 (GraphPad Software Inc., La Jolla, CA, USA) and IBM Corp. Released 2013, IBM SPSS Statistics for Windows, Version 22.0. Armonk, NY: IBM Corp. All data were analyzed using nonparametric statistics, unless otherwise stated. All $p$-values were two-sided and considered to be statistically significant when $p<0.05$. For correlations involving plasma cytokine levels, $p$-values were adjusted for multiple comparisons using a false discovery rate (FDR) procedure, according to the Benjamini and Hochberg method, with R Project software v. 3.4.1 (R Foundation for Statistical Computing, Vienna, Austria). Adjusted $p$-values were considered significant when less than 0.1. Finally, data was analyzed by machine learning methods. Variable hierarchization was performed by Weka [37] (http:/ / www.cs.waikato.ac.nz/ml/weka/v.3.7) using correlation-based feature selection and J48 decision tree. Pictures of decision trees were made using KNIME Analytics Platform (http:/ / www.knime.comv3.4). Only trees with accuracy (of classification) and k-Cohen [38] values above 0.7 and 0.6 , respectively, were reported as significant.

A.

Dichotomic classes used to construct decision trees

$\mathrm{C} 1$ : Defined "progressors" as subjects whose $\mathrm{CD}^{+} \mathrm{T}$-cell count dropped below 350 cells $/ \mu \mathrm{L}$ at any time during the first year postinfection

C2: Segregated subjects according their baseline VL was above $5 \log _{10}$ RNA copies/mL.

C3: Segregated subjects according their VL was above $5 \log _{10}$ RNA copies $/ \mathrm{mL}$ at six month post-infection.

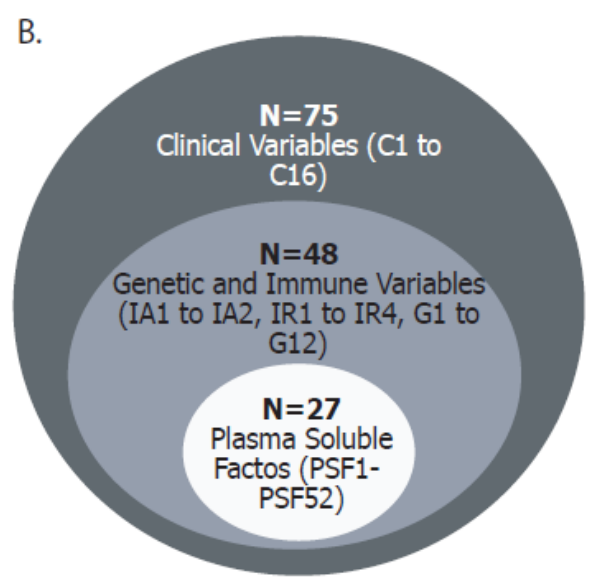

Figure 1. (A) Definition of the three classes (C1, C2 and C3) used in this study to segregate subjects into "progressors" and "non-progressors" or in relation to their ability to control viral replication. These classes were used to construct decision trees. (B) The whole database was subdivided into three self-including parts, i.e., the small database $(N=27)$, the intermediate base $(N=48)$ and the entire base $(N=75)$. The dataset used in each analysis is indicated in the text. $\mathrm{CD} 4^{+}$and $\mathrm{CD} 8^{+} \mathrm{T}$-cell counts and viral load (VL) were determined in all subjects. Additionally, Human Leukocyte Antigen (HLA) and C-C chemokine receptor type 5 (CCR5) genotyping (and the corresponding genetic scores (GS, Appendix A)), HIV-specific immune responses and immune activation were determined in a subset of 48 subjects. Finally, 40 plasma soluble factors (39 cytokines and chemokines plus lipopolysaccharide (LPS) were quantified in a smaller group $(N=27)$. The values obtained for each soluble factor were used individually but also additive scores were constructed (CS, cytokine scores, Appendix A variables plasma soluble factor (PSF)41 to PSF52). IA: Immune activation; IR: Immune response. 


\section{Results}

\subsection{Cohort Description}

A total of 75 recently-infected HIV positive $\left(\mathrm{HIV}^{+}\right)$subjects were enrolled. The summary of subject's characteristics is shown in Table 1. Eighty percent of enrolled subjects were identified on the bases of presenting symptoms compatible to acute retroviral syndrome. Baseline samples were obtained at a median of 75 days after the presumed date of infection. Most of the subjects were on Fiebig $\mathrm{V}$ at enrollment. Medical and laboratory evaluation $\left(\mathrm{CD} 4^{+} \mathrm{T}\right.$-cell count and $\left.\mathrm{VL}\right)$ were performed at enrollment (baseline sample) and through one year. For the purposes of this study, data were recorded as long as subjects remained off-ART. Thus, sample size dropped to $N=59$ and $N=46$ at 6 and 12 months postinfection, respectively. $\mathrm{CD}^{+}$and $\mathrm{CD}^{+} \mathrm{T}$-cell counts and $\mathrm{HIV}^{+}$plasma viral load were determined longitudinally in the whole set of subjects (Table 1, Figure 2A,B). CD4 ${ }^{+}$T-cell count was significantly lower at the 12 -month sample compared to baseline $(p=0.001)$. Although CD4 ${ }^{+} \mathrm{T}$-cell counts were not determined in healthy donors (HD) enrolled for this study, unpublished data from our group indicate that median $\mathrm{CD} 4^{+} \mathrm{T}$-cell counts for a similar adult population from our country $(N=118)$ is 834 cells $/ \mu \mathrm{L}$ (IQR25-75\% = 627-1080). This is significantly higher (Mann-Whitney test $p<0.0001$ ) compared to the baseline sample from the $\mathrm{HIV}^{+}$subjects thus reflecting the early attrition of the $\mathrm{CD}^{+}{ }^{+} \mathrm{T}$-cell subset which is characteristic of HIV infection. On the other hand, baseline VL was significantly higher than 6-month and 12-month VLs $(p<0.0001$ and $p=0.0026$, respectively). However, no difference was observed between 6-month and 12-month VLs, indicating that a set-point was already established. Baseline immune activation was determined in a subset of 48 subjects. At the CD8 ${ }^{+} \mathrm{T}$-cell compartment, it was significantly higher than in healthy donors evidenced by higher percentages of CD8 ${ }^{+}$T-cells expressing CD38 $(p<0.001)$ and CD38/HLA-DR $(p=0.0006)$ (Table 1, Figure 2C).

Table 1. Characteristics of $\mathrm{HIV}^{+}$subjects enrolled in this study.

\begin{tabular}{|c|c|c|c|}
\hline \multirow{4}{*}{\multicolumn{2}{|c|}{$\begin{array}{l}\text { Total sample size (number of individuals) } \\
\text { Female:Male ratio } \\
\text { Age at enrollment (years, median and IQR25-75\%) } \\
\text { Estimated time of infection at enrollment (days, } \\
\text { median and IQR25-75\%) }\end{array}$}} & \multicolumn{2}{|c|}{75} \\
\hline & & \multicolumn{2}{|c|}{$1: 3$} \\
\hline & & \multicolumn{2}{|c|}{$30(24-38)$} \\
\hline & & \multicolumn{2}{|c|}{$75(54-113)$} \\
\hline \multicolumn{4}{|c|}{ Follow-up of Virologic and Immune Characteristics: } \\
\hline & Baseline $(N=75)$ & 6-month pi $(N=59)$ & 12-month pi $(N=46)$ \\
\hline $\begin{array}{l}\text { VL (RNA copies/mL; median } \\
\text { and IQR25-75\%) a }\end{array}$ & $61,045(12,736-455,417)$ & $18,951(4298-62,739)$ & $16,988(5695-40,105)$ \\
\hline $\log _{10} \mathrm{VL}(\text { mean } \pm S D)^{a}$ & $4.6 \pm 1$ & $4 \pm 1$ & $4 \pm 0.89$ \\
\hline $\begin{array}{l}\mathrm{CD} 4^{+} \text {T-cell count (cells } / \mu \mathrm{L} \text {, } \\
\text { median and IQR25-75\%) }\end{array}$ & $525(361-698)$ & $571(406-673)$ & $464(387-585)$ \\
\hline $\begin{array}{l}\text { CD4/CD8 Ratio (Median and } \\
\text { IQR25-75\%) }\end{array}$ & $0.6(0.32-0.83)$ & $0.55(0.34-0.8)$ & $0.61(0.39-0.93)$ \\
\hline $\begin{array}{l}\mathrm{CD} 4^{+} \mathrm{T}-\text { cell decay rate } \\
\text { (cells/ } \mu \mathrm{L} / \text { day; median and } \\
\text { IQR25-75\%) }\end{array}$ & & $-0.62(-0.31--0.03)$ & \\
\hline \multicolumn{4}{|c|}{ Baseline Immune Activation (\%cells, median and IQR25-75\%) c: } \\
\hline$\% \mathrm{CD} 4^{+} \mathrm{CD}^{2} 8^{+}$ & & $24.4(16-36.2)$ & \\
\hline$\% \mathrm{CD}^{+} \mathrm{HLA}-\mathrm{DR}{ }^{+}$ & & $4.6(1.5-11.01)$ & \\
\hline$\% \mathrm{CD}^{+}{ }^{+} \mathrm{CD} 38^{+} \mathrm{HLA}-\mathrm{DR}{ }^{+}$ & & $1.2(0.47-2.8)$ & \\
\hline$\% \mathrm{CD}^{+} \mathrm{CD}^{-} 8^{+}$ & & $45.2(21.3-57.1)$ & \\
\hline$\% \mathrm{CD}^{+}{ }^{+} \mathrm{HLA}-\mathrm{DR}{ }^{+}$ & & $26.5(15.2-41)$ & \\
\hline$\% \mathrm{CD}^{+} \mathrm{CD} 8^{+} \mathrm{HLA}-\mathrm{DR}{ }^{+}$ & & $13.8(6.7-30.6)$ & \\
\hline
\end{tabular}


A total of 88 variables, including those described in the preceding paragraph were recorded in enrolled subject (Appendix A). Due to technical limitations, some of these parameters were determined in smaller cohort subsets (see Figure 1). Thus, plasma LPS, cytokines and chemokines were determined in 27 subjects. These data were used to construct 12 cytokine-based scores (CS, Appendix A variables PSF41 to PSF52). Similarly, immune activation, HLA and CCR5 genotypes, genetic scores (GS, Appendix A variables G1 to G10) as well as magnitude and percentages of Nef- and Gag-specific immune cells were determined in 48 subjects. Gender ratio and median age at enrollment were similar across the three datasets.

\section{A. CD4 ${ }^{+}$T-cell count}

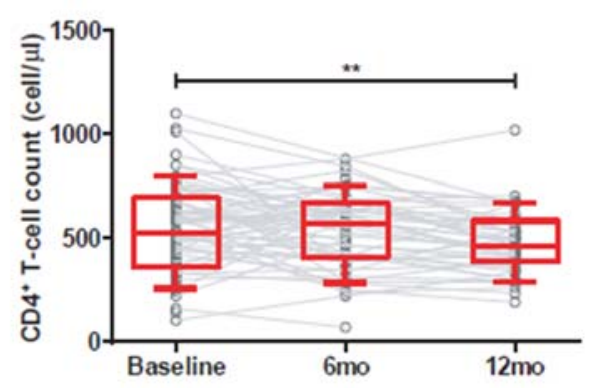

C. Baseline Immune Activation

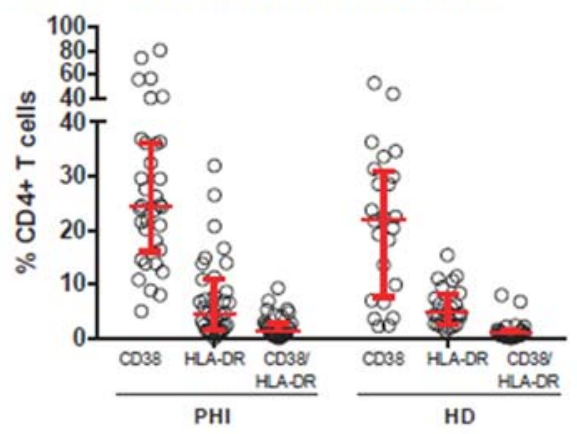

\section{B. Plasma Viral Load}
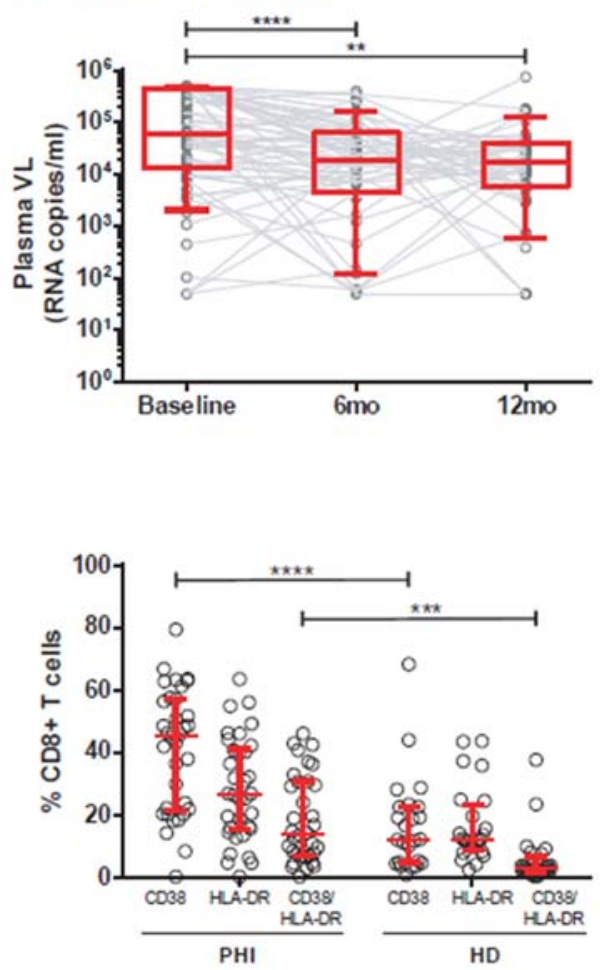

Figure 2. $\mathrm{CD}^{+}$T-cell counts, plasma viral load (VL), and immune activation of enrolled subjects. All samples were obtained as long as the subjects remained treatment naïve. Longitudinal determination of $\mathrm{CD}^{+}{ }^{+}$T-cell counts (A); and plasma viral load (B) are shown (Baseline = enrollment sample, 6 and 12 months postinfection). Dots represent data from individual subjects and lines join matched values for each subject. Boxes represent the interquartile 25-75\% range (IQR25-75) and whiskers extend from 10th to 90th percentiles. Horizontal lines within boxes represent the median. Immune activation (C) was evaluated at baseline as the percentage of CD38 ${ }^{+}$, HLA-DR ${ }^{+}$ or $\mathrm{CD}_{3} 8^{+} / \mathrm{HLA}-\mathrm{DR}^{+} \mathrm{CD}^{+}$(left panel) or $\mathrm{CD}^{+}$(right panel) T-cells. Dots represent data from individual subjects. Median and IQR25-75 are shown in red. In A and B, $p$-values were calculated using Wilcoxon test (baseline versus 6-month or 12-month samples). In $C$, $p$-values were calculated using Kruskal-Wallis test followed by Dunn's post-test to compare preselected pairs of datasets. PHI: Primary HIV infection cohort. HD: Healthy donors. Asterisks denote $p$-values as follows: ${ }^{* *} p<0.01$, ${ }^{* * *} p<0.005,{ }^{* * * *} p<0.0001$.

\subsection{Association of Individual Parameters with Disease Progression}

We have previously described certain variables that, individually, were associated with disease progression in this cohort. For the purpose of this study we chose to include the following variables in this new analysis: immune activation because its level early after infection was associated with disease progression [31] (variables IA1-IA6, see Appendix A), HIV-specific T-cell specificity because we have shown that early Gag immunodominance was associated with slow rates of disease progression [28] 
(magnitude and percentages of Nef and Gag-specific T-cells; variables IR1-IR4), and genetic scores built based on subject's HLA and CCR5 genotypes because one score was previously associated with lower baseline VL in this cohort [30] (variables G1-G8). These variables were chosen from the whole set of variables that we investigated in this cohort, based on their strong association with disease progression, and for their practicability to be measured in case it could be translated into the clinical setting. In addition to this, cytokines, chemokines and LPS were evaluated in plasma from enrolled subjects at baseline sample. Since the behavior of these variables in this cohort has not been described previously, we first analyzed the expression of these factors in comparison to HD and its association with markers of disease progression.

Out of the 39 cytokines and chemokines evaluated in plasma from enrolled subjects $(N=27)$, six were significantly increased during PHI compared to HD: IL-1 $\alpha$, IL-10, IP-10, MIP-1 $\alpha, \operatorname{sIL}-2$ R $\alpha$, and TNF- $\alpha$. The highest increase was observed for sIL-2R $\alpha$ which was seven-fold higher in PHI compared to HD. This was followed by IL-1 $\alpha$, IL-10, MIP- $1 \alpha$, and IP-10 which were three times elevated in PHI compared to HD, and TNF- $\alpha$ which was 1.7 times elevated in PHI. All but MIP-1 $\alpha$ remained significantly elevated after adjustment for multiple comparisons (FDR procedure). IL-15 was significantly lower in PHI compared to HD (around 30\% lower), even after FDR correction (Figure 3). Then, we aimed to study interconnection of cytokines both in HD and in PHI, following the rational proposed by Huang et al. [39]. For this, correlation analyses were performed among all cytokines in both groups. In HD, 144 out of 647 correlations evaluated were statistically significant (22.7\%) while this ratio was 252/740 (34\%) in PHI. Of those significant correlations, the r coefficients were significantly higher in HD (median $=0.7335$, IQR25-75 $=0.6755-0.8215$ ) compared to PHI (median $=0.4935 \mathrm{IQR} 25-75=0.435-0.555, p<0.0001)$. Compared to HD, 68 significant correlations were maintained in PHI, 71 significant correlations were lost, and 180 new significant correlations emerged. This evidenced a rearrangement of the cytokine network during PHI, compared to HD.

Then, the relation of each cytokine and chemokine with $\mathrm{CD}^{+} \mathrm{T}$-cell counts, plasma VL and immune activation were determined. Baseline plasma levels of G-CSF and IP-10 inversely correlated with baseline, 6-month and 12-month $\mathrm{CD}^{+}$T-cell percentages (\%CD4 ${ }^{+}$T-cells). Similarly, baseline plasma sIL-2R $\alpha$ inversely correlated with baseline $\% C D 4^{+}$T-cells while baseline plasma IL-1 $\alpha$ and MCP-3 inversely correlated with 12-month \%CD4 ${ }^{+}$T-cells. In the same line, baseline plasma IFN $\alpha 2$, IL-8, MCP-1 directly correlated with CD4 slope (Figure 4). However, all these associations lost statistical significance after FDR adjustment. On the other hand, baseline plasma IL-10, IP-10, TNF- $\alpha$ and sIL-2R $\alpha$ directly correlated with baseline VL and remained significant after adjustment (Figure 5). However, no statistically significant association was found between cytokine and chemokine levels and 6-month or 12-month VL. Of note, subjects with over-limited baseline VLs (>500,000 RNA copies $/ \mathrm{mL})$ were included in the analysis by setting the corresponding values at 500,000 . The same analysis was repeated excluding these values and all correlations remained statistically significant except for IP-10. However, it should be noted that IP-10 is consistently found in the bibliography directly associated with VL (See the discussion section). Thus, this lack of correlation is most likely the result of reducing significantly the sample size (from 27 to 18) and the presence of one outlier. Finally, correlations between these plasma molecules and baseline immune activation (defined as percentages of $\mathrm{CD}^{+} \mathrm{CD}^{+} 8^{+} \mathrm{HLA}-\mathrm{DR}^{+}$and $\mathrm{CD}^{+} \mathrm{CD} 38^{+} \mathrm{HLA}^{-\mathrm{DR}}{ }^{+} \mathrm{T}$-cells) were studied. Baseline IL-2, TNF- $\alpha$, FGF-2 and MIP-1 $\beta$ directly correlated with percentages of activated CD4 ${ }^{+}$T-cells, while IL-2, TNF- $\alpha$, GM-CSF and GRO directly correlated with percentages of activated CD8 ${ }^{+}$T-cells (Figure 5). However, only those correlations involving percentages of activated $\mathrm{CD} 4^{+} \mathrm{T}$-cells remained significant after FDR adjustment. In summary, a few cytokines and chemokines, most of them associated with a pro-inflammatory profile except for IL-10, were elevated in PHI compared to HD. In contrast, IL-15 was diminished. Some associations were found between baseline levels of these cytokines and CD4 ${ }^{+} \mathrm{T}_{\text {-cell }}$ count along time and also with $\mathrm{CD}^{+} \mathrm{T}$-cell decay rate (CD4 slope). Though, these correlations lost significance after correction, suggesting that they might not represent truly associations. Conversely, correlations between IL-10, IP-10, TNF- $\alpha$ and sIL-2R $\alpha$ and VL remained significant but they were 
only associated with baseline VL and not with 6-month and 12-month VL, which suggests that these molecules may not have any predictive value over the course of infection but they would only be related to the level of concurrent viral replication. No significant correlation was found between baseline plasma LPS levels and CD4 ${ }^{+}$T-cell counts or plasma VL at any time-point.
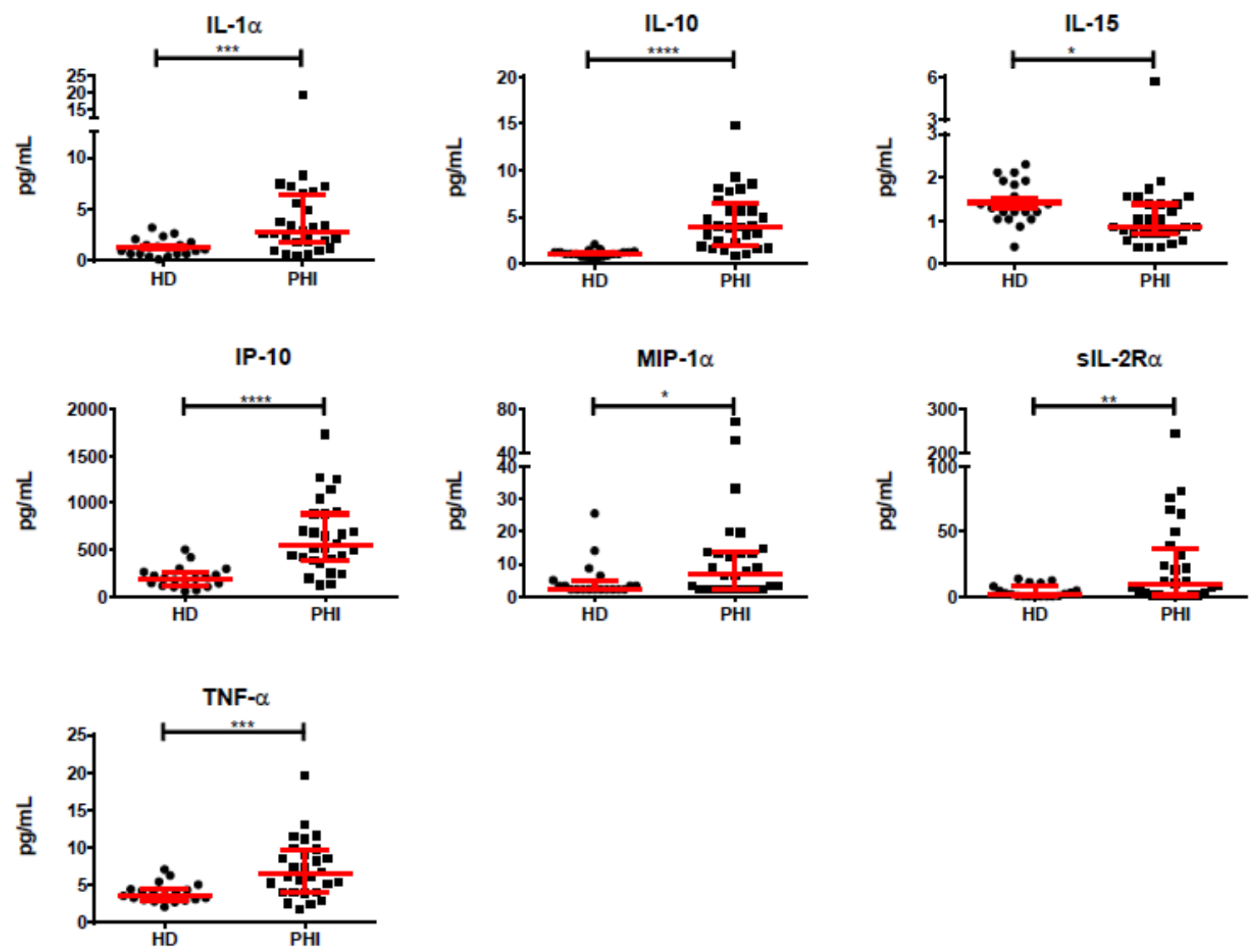

Figure 3. Plasma levels of IL- $1 \alpha$, IL-10, IL-15, IP-10, MIP- $1 \alpha$, sIL-2R $\alpha$, and TNF- $\alpha$ in samples obtained at enrollment of recently infected $\mathrm{HIV}^{+}$subjects (PHI, baseline samples) and healthy donors (HD). Dots represent data from individual subjects. Median and interquartile ranges (IQR25-75) are shown in red. $p$-values were calculated using Mann-Whitney test. Asterisks denote $p$-values as follows: ${ }^{*} p<0.05$, ${ }^{* *} p<0.01,{ }^{* * *} p<0.005,{ }^{* * * *} p<0.0001$. After false discovery rate (FDR) adjustment, all but macrophage inflammatory protein (MIP)- $1 \alpha$ remained significantly different. 
A.

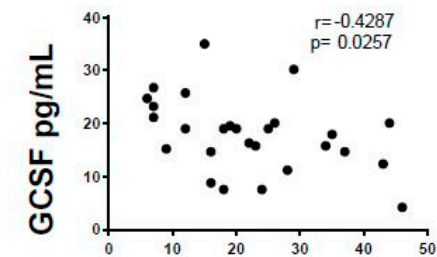

Baseline \%CD4

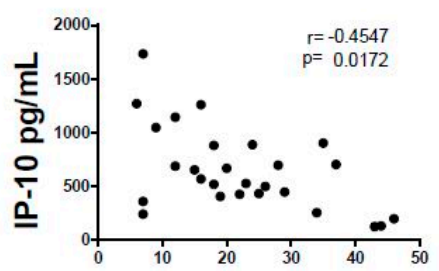

Baseline \%CD4

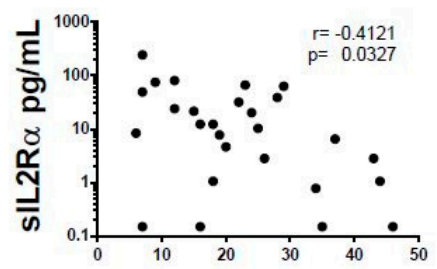

Baseline \%CD4

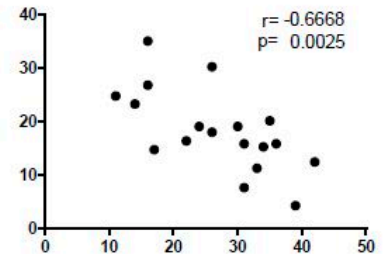

$6 \mathrm{mo} \% \mathrm{CD} 4$

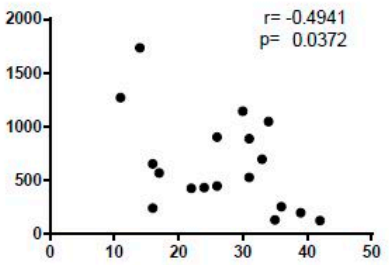

$6 \mathrm{mo} \% \mathrm{CD} 4$

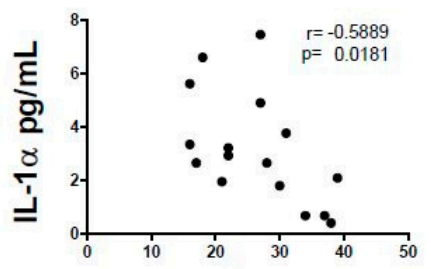

$12 \mathrm{mo} \% \mathrm{CD} 4$

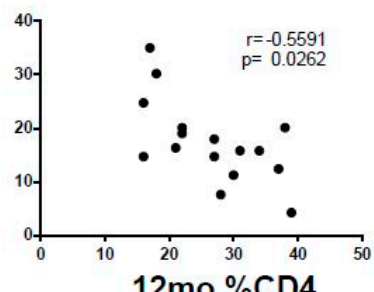

$12 \mathrm{mo} \% \mathrm{CD} 4$

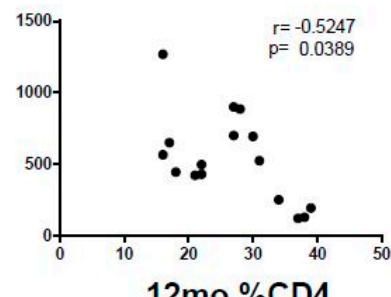

$12 \mathrm{mo} \% \mathrm{CD} 4$

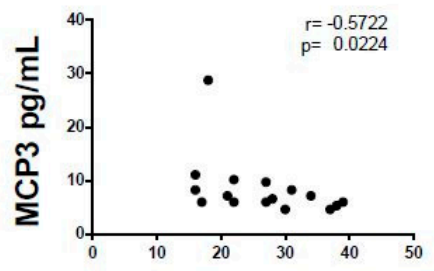

$12 \mathrm{mo} \% \mathrm{CD} 4$

B.
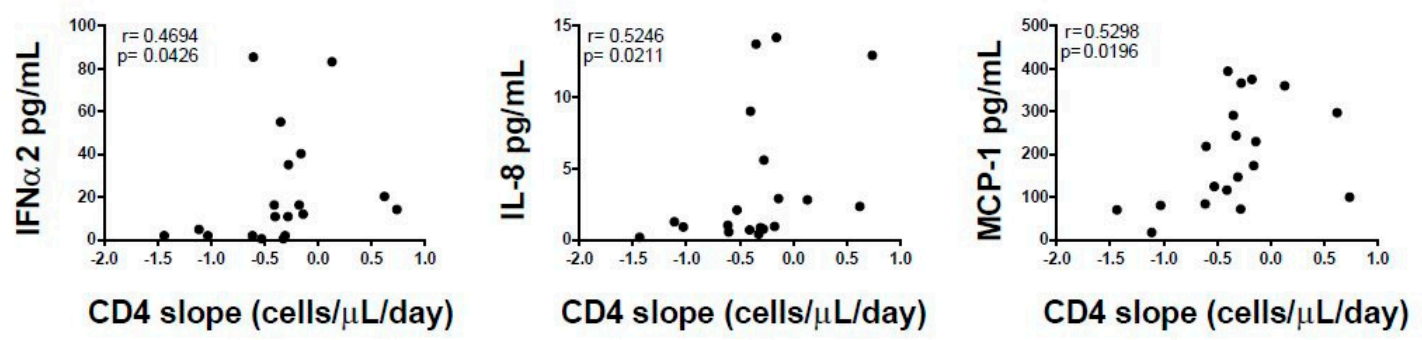

Figure 4. (A) Correlations between plasma level of denoted cytokines and chemokines (evaluated at baseline samples) versus percentages of $\mathrm{CD} 4^{+} \mathrm{T}$-cells evaluated at the denoted time-points. (B) Correlations between the plasma level of denoted cytokines and chemokines (evaluated at baseline samples) versus daily $\mathrm{CD} 4{ }^{+} \mathrm{T}$-cell count decay rate (CD4 slope, cells $/ \mu \mathrm{L} /$ day). Dots represent data from individual subjects. In the inset, $r$ (upper line) and $\mathrm{p}$ (lower line) values correspond to Spearman's test. After correction for multiple comparisons (FDR procedure) was applied, none of these correlations remained statistically significant. 

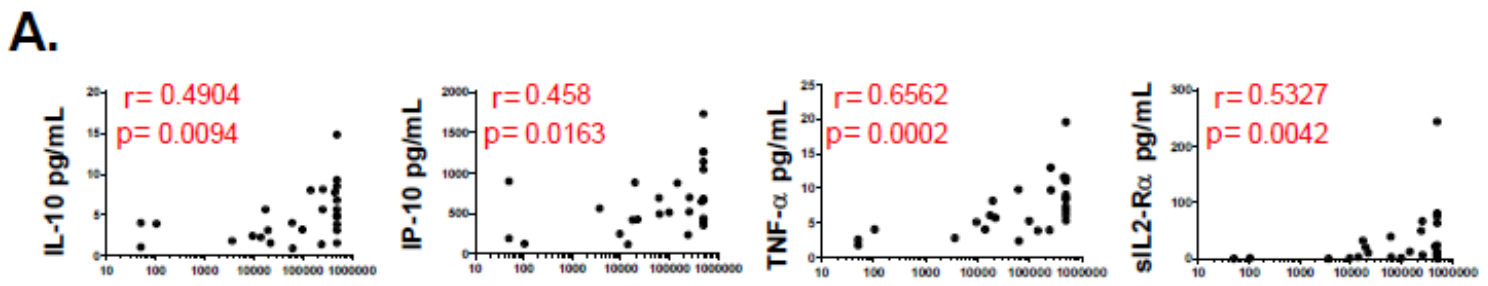

\section{Baseline VL (RNA copies/mL)}
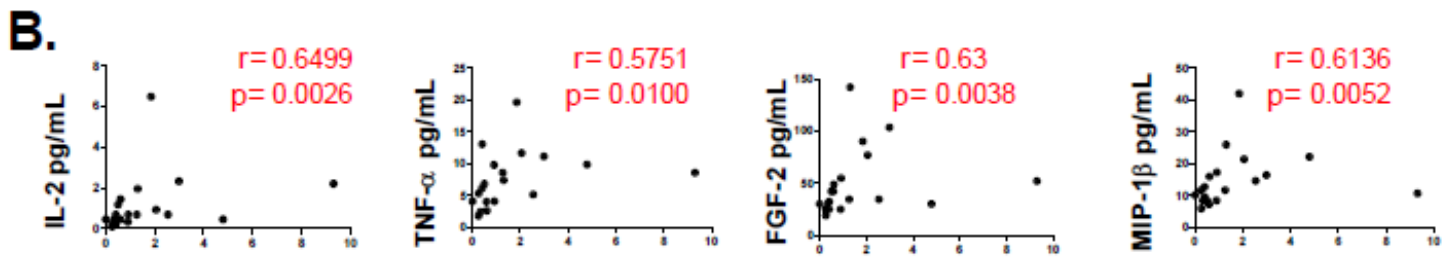

\section{$\%$ Activated $\mathrm{CD} 4^{+} \mathrm{T}$ cells}
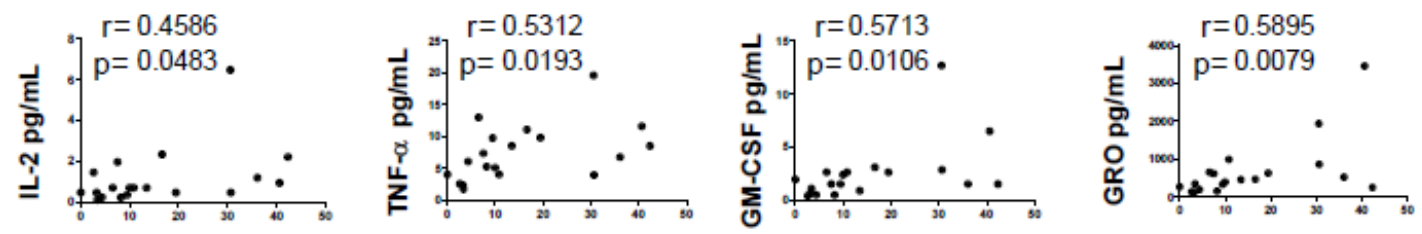

\section{$\%$ Activated $\mathrm{CD}^{+}{ }^{\mathrm{T}}$ cells}

Figure 5. Correlations between plasma level of denoted cytokines and chemokines (evaluated at baseline samples) versus: plasma viral load (VL) (A); and baseline immune activation (B) (percentages of $\mathrm{CD}^{2} 8^{+} / \mathrm{HLA}-\mathrm{DR}^{+} \mathrm{CD} 4^{+}$(upper panels) and $\mathrm{CD} 8^{+}$(lower panels) T-cells). Dots represent data from individual subjects. In the inset, $\mathrm{r}$ (upper line) and $\mathrm{p}$ (lower line) values correspond to Spearman's test. After correction for multiple comparisons (FDR procedure) was applied, only those correlations shown in red remained statistically significant.

\subsection{Baseline CD4 $4^{+}$T-cell Count Was the Most Potent Variable to Distinguish "Progressors" from "Non-Progressors"}

Then, we aimed to weight the association of each variable with disease progression. For this purpose, three individual discrete dichotomic classes were constructed to segregate subjects according the criteria described in Materials and Methods section, and as shown in Figure 1A. In addition, for these analyses the whole database was subdivided into three self-including parts, i.e., the small database $(N=27)$, the intermediate database $(N=48)$ and the whole database $(N=75)$ (see Methods and Figure 1B). First, correlations between $\mathrm{C} 1, \mathrm{C} 2$ and $\mathrm{C} 3$ with all other individual variables as well as cytokine-based and genetic scores were studied using Weka correlation based feature selection along the three databases (Figure 6A). Strong correlations $(r>0.6)$ were mainly found with clinical parameters: baseline $\mathrm{CD} 4^{+} \mathrm{T}$-cell counts, baseline $\mathrm{CD} 4^{+} \mathrm{T}$-cell percentages and baseline CD4/CD8 ratios strongly correlated with $\mathrm{C} 1$ ( $r=0.8321,0.7495$ and 0.6493 , respectively). The $\mathrm{r}$ values correspond to correlations studied based on the small database $(N=27)$, although they remained above 0.6 when repeating the analyses with the intermediate database (0.7944, 0.6901 and 0.6535 , respectively). However, only baseline $\mathrm{CD}^{+} \mathrm{T}$-cell counts and baseline $\mathrm{CD} 4^{+} \mathrm{T}$-cell percentages strongly correlated with class $\mathrm{C} 1$ when using the largest dataset (0.7210 and 0.62983, respectively). CST4 (Appendix A) and baseline $\mathrm{CD}^{+}$T-cell counts strongly correlated with $\mathrm{C} 2(r=0.62307$ and 0.6130 , respectively) in 
the small database. However, the magnitude of the latter association was lost when using the bigger database. Surprisingly, no strong correlation was found when studying C3 in all the analyses.

\begin{tabular}{|c|c|c|}
\hline & $\mathrm{C} 1$ & $\mathrm{C} 2$ \\
\hline $\begin{array}{l}\text { Small Database } \\
(\mathrm{N}=27)\end{array}$ & $\begin{array}{c}\text { Baseline CD4 }=0.8321 \\
\text { Baseline CD4\% }=0.7495 \\
\text { Baseline } C D 4 / C D 8 \text { ratio }=0.6493\end{array}$ & $\begin{array}{c}\text { CST } 4=0.6230 \\
\text { Baseline CD } 4=0.6130\end{array}$ \\
\hline $\begin{array}{l}\text { Medium Database } \\
(\mathrm{N}=48)\end{array}$ & $\begin{array}{c}\text { Baseline CD4 }=0.7944 \\
\text { Baseline CD4\% }=0.6901 \\
\text { Baseline } C D 4 / C D 8 \text { ratio }=0.6535\end{array}$ & None \\
\hline $\begin{array}{l}\text { Large Database } \\
(\mathrm{N}=75)\end{array}$ & $\begin{array}{l}\text { Baseline CD4 }=0.6230 \\
\text { Baseline CD4\%=0.6130 }\end{array}$ & None \\
\hline
\end{tabular}

B. Progression class: $\mathrm{C} 3$ Database: Medium

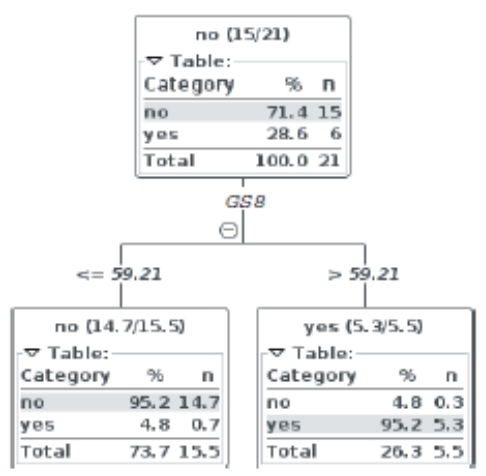

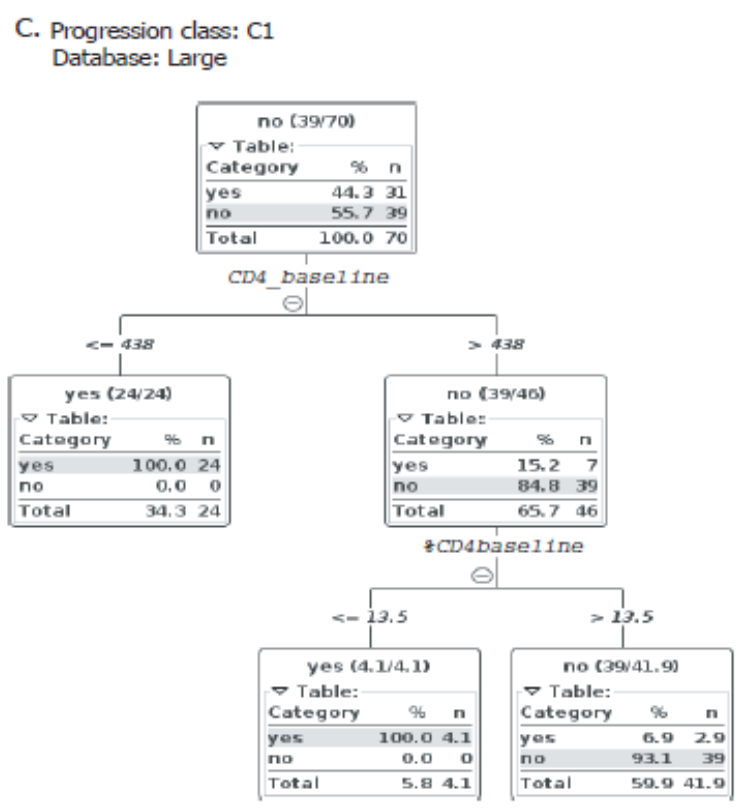

D.

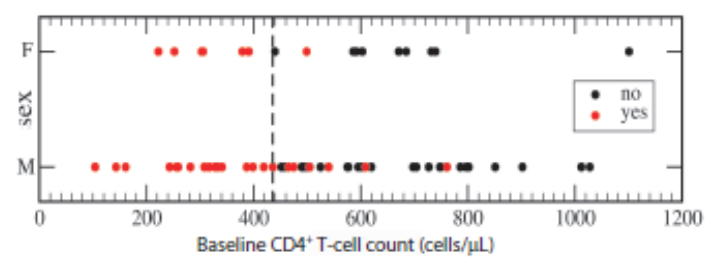

Figure 6. (A) Variable hierarchization using correlation based feature selection between classes C1 and C2 with all other individual variables as well as cytokine-based (CS) and genetic scores (GS), along with the three databases (small $(N=27)$, medium $(N=48)$, and large $(N=75)$ ). Only strong correlations $(>0.6)$ are shown. No correlation was found between the variables studied and C3. Decision trees were constructed to discriminate "progressors" from "non-progressors" as defined by: C3 (B); and $\mathrm{C} 1(\mathbf{C})$. To build the tree shown in (B), the clinical variables were not included in the analysis. (D) Baseline $\mathrm{CD}^{+}$T-cell counts of the individuals enrolled segregated as "progressors" (yes, red dots) and "non-progressors" (no, black dots) according to C1. The cut-off value as defined by the tree shown in C is depicted by the vertical dashed line. CST4: cytokine score CST4 (see Appendix A). GS8: genetic score 8 (see Appendix A). The number of instances considered in D and C was the result of the elimination of cases with missing class value.

Then, with the aim of detecting the most predictive variables for infection progression, J48 decision trees were constructed using different sets of variables on the three self-including databases. Thus, for each database, trees were automatically generated using the whole set of variables (including genetic and cytokine-based scores), the intermediate subset of variables (all variables excluding the clinical dataset) and a small set of variables comprising only the cytokine-related variables. By using this methodology, none of the cytokine-related or immune (immune activation or immune responses) variables had good predictive value to distinguish between the groups of subjects segregated according to C1, C2 or C3. Only GS8 (Appendix A) could discriminate "high 6-month VL" from "low 6-month $\mathrm{VL}^{\prime}$ " as defined by $\mathrm{C} 3$ with good power (accuracy $=0.905$, $\mathrm{k}$-Cohen $=0.767$, Figure $6 \mathrm{~B}$ ), provided the clinical variables were not included in the analysis. The resulting tree had only one branch that split the feature GS8 with a cut-off value=59.21: most of the "6-month VL below $10^{5}$ " subjects 


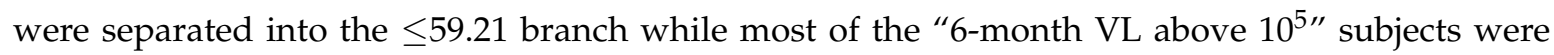
separated into the $>59.21$ branch. When the clinical parameters were included in the dataset to build the trees, these variables always outcompeted all other variables including the cytokine and genetic scores, i.e., immune activation, HIV-specific immune responses, HLA haplotypes and soluble factors had lower discrimination power when compared to clinical parameters. Always, the clinical parameters were included in the analysis, and baseline $\mathrm{CD} 4^{+} \mathrm{T}$-cell count was the most potent variable to distinguish "progressors" from "non-progressors" defined by $\mathrm{C} 1$ with a cut-off of 438 cells $/ \mu \mathrm{L}$ in the $N=75$ database (accuracy $=0.929, \mathrm{k}-\mathrm{Cohen}=0.853$; Figure $6 \mathrm{C}, \mathrm{D}$ ). Here, most "progressors" and no "non-progressors" were separated into the $\leq 438$ branch. The $>438$ branch contained $15 \%$ "progressors" and $85 \%$ "non-progressors" that could be separated into a subsequent branch by the baseline percentage of $\mathrm{CD}^{+}{ }^{-} \mathrm{T}$-cells.

\section{Discussion}

Progression of HIV infection is variable among individuals and the definition of disease progression biomarkers is still fundamental. Apart from CD4 ${ }^{+} \mathrm{T}$-cell count and VL, several parameters individually showed associations with the rate of disease progression, as shown by our group and others [11-31]. Here, we took advantage of results found in our well characterized cohort of acute/early HIV infected subjects from Argentina. This cohort was fully enrolled in our country, and the vast majority of the subjects enrolled are native, which distinguishes this cohort from others from Africa, Europe and Asia. The analysis included a rich dataset of 16 clinical variables, six immune activation variables, four cellular immune response variables, 10 genetic variables and 52 variables related to plasma soluble factors. The behavior of some of these variables in this cohort, in particular their individual associations with disease progression, has been described elsewhere [27-31]. The aim of the study was to categorize their predictive potential using decision trees and to analyze their possible implementation in the clinical setting.

The so-called "cytokine storm" occurring during the first weeks after HIV infection is a well-known phenomenon [18,39-41]. In line with this, plasma levels of IL-1 $\alpha$, IL-10, IP-10, sIL-2R $\alpha$, and TNF- $\alpha$ were significantly elevated (from 1.7 to 7 times) in the baseline samples from subjects enrolled in the cohort, compared to HD. The elevation of IL-1 $\alpha$, IP-10, sIL-2R $\alpha$, TNF- $\alpha$ may be indicating the activation of a pro-inflammatory response, not only to HIV-encoded pathogen-associated molecular patterns (PAMPs) but also to bacterial PAMPs exposed as a result of the gut-associated lymphoid tissue early disruption [1,42]. IL-10 elevation might be the result of an attempt to control the pro-inflammatory burst $[18,43]$. In addition, it depicts the activation of innate immunity effectors and also T-cells. On the other hand, a modest albeit significant reduction in IL-15 was observed. This cytokine play key roles in both innate and adaptive responses by participating in the expansion and differentiation of Natural Killer (NK) cells and also by contributing to the homeostasis of the memory T cell pool. Several reports indicated that IL-15 was elevated during HIV acute infection [18,40,44,45] while others reported no changes $[15,16]$. These discrepancies could be attributed to the fact that IL-15 peaks very fast after infection and then sharply decays $[39,41,44]$. Thus, sampling time after infection can significantly affect the results. Apart from the mere increment in the plasma concentration of cytokines, a more intricate relationship between all cytokines was observed in acute infection, compared to HD, evidenced by the rearrangement of correlations among the cytokines studied. This is in line with a recent report indicating that HIV imposes a new order on the cytokine network, which in turn could contribute to disease [39].

Correlation analysis between plasma cytokines in baseline samples revealed several associations with clinical parameters such as $\mathrm{CD} 4^{+} \mathrm{T}$-cell count, viral load and immune activation either evaluated in the same or in subsequent samples. All correlations involving $\mathrm{CD}^{+} \mathrm{T}$-cell count (including CD4 slope) and $\mathrm{CD} 8^{+} \mathrm{T}$-cell activation lost significance after adjustment for multiple comparison. Conversely, IL-2, TNF- $\alpha$, FGF- 2 and MIP-1 $\beta$ remained significantly correlated with concurrent CD4 ${ }^{+}$T-cell activation. Noel et al. have reported that plasma levels of IP-10, sCD163, IL-6 and MCP1 directly correlated 
both with $\mathrm{CD}^{+}$and $\mathrm{CD}^{+} \mathrm{T}$-cell activation (measured as percentage of CD38 ${ }^{+} \mathrm{HLA}-\mathrm{DR}{ }^{+}$cells) in a cohort of chronically-infected HIV controllers [46]. More relevant to our context, Liovat et al. reported that levels of IP-10, IL-18 and TGF- $\beta 1$, measured early after infection, correlated with CD8 ${ }^{+} \mathrm{T}_{\text {-cell }}$ activation measured at six months postinfection, but $\mathrm{CD}^{+} \mathrm{T}$-cell activation was not evaluated [16]. The fact that associations (and the strength of those associations) between individual cytokines and immune activation differed whether the evaluation was performed in the $\mathrm{CD} 4^{+}$or the $\mathrm{CD} 8^{+} \mathrm{T}$-cell compartment provides support to the notion that different forces (for instance, immune homeostasis or viral replication itself), could be driving cellular activation in each compartment [43]. Above all, the strongest correlations were those found between baseline levels of IL-10, IP-10, TNF- $\alpha$ and sIL-2R $\alpha$ with baseline VL. Of note, these cytokines did not correlate with subsequent VL values suggesting that they might have no predictive value over VL course, at least in this cohort. Instead, these associations might be reflecting that the magnitude of the "cytokine storm" is directly or indirectly influenced by the magnitude of concurrent viral replication as suggested by others [15,18,39]. Of note, these cytokines belong to divergent families and, with the exception of SIL2R $\alpha$, they have also been associated previously with the magnitude of HIV replication during acute infection [15,16]. TNF- $\alpha$ is a potent effector of the antiviral immunity and also can increase viral replication by enhancing proviral transcription. Suppressor activity of IL-10 might help control immune-mediated damage during infection and also limits HIV-specific response favoring viral persistence. IP-10 (or C-X-C motif chemokine (CXCL)-10) is a chemokine induced by IFN- $\gamma$, which has been consistently found to be elevated in different stages of HIV infection, including acute/early infection, and it has been mostly associated with the worst-case scenarios in terms of disease progression [15,39,46-51]. In particular, two studies [16,52] identified IP-10 level during acute infection as a predictor of rapid disease progression. Although in this work baseline IP-10 correlated with concurrent VL, it failed to predict subsequent VL or discriminate progressors from non-progressors, as in the publications mentioned.

Finding an early marker of disease progression is not a new concept but it has been proven to be a very difficult task. For instance, Roberts et al. [15] have developed a model to predict the VL set point and also a risk score of progression, both based on measuring a panel of plasma cytokines early after infection. Those equations in our cohort were tested but the outcome was unsuccessful in terms of progression prediction. The cohort used by Roberts et al. included exclusively African women, and showed a high prevalence of sexually transmitted infections other than HIV. On the contrary, our cohort comprises Caucasian men mainly. This, together with other limitations of our study, which are mentioned below, could explain the negative results when trying to apply their model in our cohort. Beyond that, it does nothing but emphasize the difficulties when trying to find a universal marker of HIV disease progression. In the same line, Mahnke et al. [12] postulated immune activation (measured as \%CD38 ${ }^{+} \mathrm{CD}^{+} \mathrm{T}$-cells), cell-associated VL (CAVL) and CD8 ${ }^{+} \mathrm{T}$-cell phenotype (\%CCR5 ${ }^{+} \mathrm{CD}^{+} \mathrm{T}$-cells) as early predictors of disease progression. While CAVL and \%CCR5 ${ }^{+} \mathrm{CD} 8^{+}$ T-cells were not measured in this study, $\% \mathrm{CD} 38^{+} \mathrm{CD} 8^{+} \mathrm{T}$-cells showed no potential as predictive factors. As in our study, HIV-specific $\mathrm{CD}^{+}$T-cell response has also been evaluated by Mahnke et al. as a possible predictor of disease progression and, in consonance with our findings, it only proved to be a weak predictor of progression over other factors.

Discordant results between this and previous studies could be explained by differences in the premises used to define disease progression, in the methodologies used to analyze the data and the time in which the baseline samples were obtained (in relation to infection date). In particular, one limitation of this study might be the wide variation in the timing of baseline sample collection and that most samples were obtained during the late acute/early infection. However, this could also be interpreted as a better reflection of the real life, since the already unusual detection of an acutely infected subject in clinics, most usually happens at Fiebig stage IV-VI. Thus, the results obtained using this kind of more "real" cohorts would be easier to translate into the real practice. Above all, the discrepancies and the difficulty in finding a reliable acute infection marker of disease progression most likely reflect the diversity and the extreme dynamics of the events that follow HIV infection. 
Here, after analyzing 88 variables in a well-defined cohort of seroconverters and where disease progression (within the first year postinfection) was defined by several means, baseline $\mathrm{CD} 4^{+} \mathrm{T}$-cell count emerged as the only variable able to predict rapid progression by machine learning methods. Many correlations between variables have been studied and several significant values were obtained. However, strong correlations do not necessarily imply predictive power over disease progression. Based on this, a two-way analysis was used: first correlations were used for filtering variables and then their predictive power was analyzed using the J48 algorithm which generates the decision trees. In an attempt to identify potential co-biomarkers of progression that may go along with $\mathrm{CD} 4^{+} \mathrm{T}$-cell count, all possibilities of analysis were exhausted, i.e., including and excluding sets of data one by one. However, these efforts were unsuccessful. Interestingly, when $\mathrm{CD} 4^{+} \mathrm{T}$-cell count was the only variable removed from the analysis, baseline VL appeared as the next variable with power to discern "progressors" from "non-progressors". No other variables (neither immune nor genetic) have been able to displace the classical parameters used to date to monitor disease progression. Thus, our approach reaffirms the predictive power of $\mathrm{CD}^{+} \mathrm{T}$-cell count (and the lack of power of the other variables) despite the scarce available data. Interestingly, the $\mathrm{CD} 4^{+} \mathrm{T}$-cell count complies with most requirements needed to be a good biomarker [5]: its assessment is objective and precise with current methodologies, it is reliable, it is directly related to the disease mechanism, and, as particularly shown in this work, it is able to identify early events in the natural history of the disease. Importantly, rapid, reliable, and affordable point-of-care CD4 tests are being developed. This will allow its rapid determination not only in centralized institutions but also in peripheral areas which will, in turn, rapidly aid in decision making and intervention [53]. In addition, this result highlights the importance of CD4 ${ }^{+}$ T-cell count for monitoring HIV infection even when there is an increasing trend to minimize its use at least in virally suppressed subjects [54,55]. Noteworthy, a significant proportion of subjects (19 out of $75,25 \%)$ had low $\mathrm{CD}^{+}{ }^{+} \mathrm{T}$-cell counts $(<350$ cells $/ \mu \mathrm{L})$ already at baseline sample, as observed also in other cohorts [56]. This emphasizes the need for interventions aimed at detecting acutely-infected subjects and at linking them to care immediately. On the other end, high baseline CD4 ${ }^{+} \mathrm{T}$-cell counts ( $>500$ cells $/ \mu \mathrm{L}$ ) were observed even in subjects that progressed rapidly after infection. This provides further support to comply with current treatment guidelines, which suggest early ART initiation.

Overall, our machine learning approach to tackling this problem was based on feature selection and decision trees. Feature selection allowed us to reduce the large number of available variables to significant ones in terms of correlation with the class. On the other hand, decision tree algorithm provides appropriate classifiers to work with scarce data and with readable outputs in a simple way. Thus, the use of feature selection and decision trees proved to be a valid methodology to weight putative biomarkers of disease progression following HIV infection. In the era of HIV cure strategies research, studies aimed at identifying biomarkers of post-treatment control are being encouraged. For instance, it is being increasingly clear that the VL magnitude reached during acute/early infection directly correlates with the reservoir size after cART is started [57,58]. In the same line, persistently high levels of pro-inflammatory cytokines after ART initiation might indicate low-level ongoing viral replication in anatomically privileged sites [59]. Altogether, elevated cytokines early after infection could impact both the seeding and the maintenance of the viral reservoir. Thus, it is tempting to hypothesize that the cytokines that were elevated during PHI in our cohort and particularly those that associated with higher baseline VL would serve as biomarkers of reservoir size after cART initiation. This would be an instrumental tool in the context of cure strategies. Thus, subsequent studies in this field using feature selection and decision trees are warrantied.

Acknowledgments: Authors specially acknowledge study participants for agreeing to participate in this study and to provide blood samples. We thank Sergio Mazzini for language assistance during manuscript preparation. This work was supported by grants from the Agencia Nacional de Promoción Cientifica y Tecnológica and GlaxoSmithKline (PICTO-GSK, Grant \# 2013/0006) and from Universidad de Buenos Aires (UBACyT 2013-2016, Grant \# 20020120200263BA) to Gabriela Turk. This investigation also used resources that were supported by the Southwest National Primate Research Center grant P51 OD011133 from the Office of Research Infrastructure 
Programs, National Institutes of Health (NIH) to Luis D. Giavedoni. The funders had no role in study design, data collection and interpretation, or the decision to submit the work for publication.

Author Contributions: Gabriela Turk, Roberto Daniel Rabinovich and Omar Sued conceived the study. Natalia Laufer, María Inés Figueroa and Omar Sued enrolled participants. Yanina Ghiglione, Macarena Hormanstorfer, Romina Coloccini, Jimena Salido, César Trifone, María Julia Ruiz, Juliana Falivene, María Pía Holgado and María Paula Caruso performed experiments. Luis D. Giavedoni provided reagents and performed experiments. Gabriela Turk, Horacio Salomón, María de los Ángeles Pando, Luis D. Giavedoni, María Magdalena Gherardi, Roberto Daniel Rabinovich and Pedro A. Pury analyzed the data. Gabriela Turk, Roberto Daniel Rabinovich, Pedro A. Pury and Omar Sued drafted the report. All authors read the manuscript, provided input into the report and approved the final version.

Conflicts of Interest: The authors declare no conflict of interest.

\section{Appendix}

Table A1. List and description of variables evaluated in this study. In addition to individual variables, scores were constructed to compile host genetic (variables G1 to G10) and plasma soluble factor (PSF41 to PSF52) data for each subject.

\begin{tabular}{|c|c|c|}
\hline Variable ID & Variable Name & Variable Description \\
\hline $\mathrm{C} 1$ & Baseline CD4 & Absolute $\mathrm{CD}^{+} \mathrm{T}$-cell count evaluated at enrollment \\
\hline $\mathrm{C} 2$ & Baseline \%CD4 & Percentage of $\mathrm{CD}^{+}{ }^{+} \mathrm{T}$-cells evaluated at enrollment \\
\hline $\mathrm{C} 3$ & Baseline CD4/CD8 & CD4/CD8 ratio evaluated at enrollment \\
\hline $\mathrm{C} 4$ & $6 \mathrm{mo}$ CD4 & Absolute $\mathrm{CD} 4^{+} \mathrm{T}$-cell count evaluated at 6 months postinfection \\
\hline C5 & $6 \mathrm{mo} \% \mathrm{CD} 4$ & Percentage of $\mathrm{CD}^{+}$T-cells evaluated at 6 months postinfection \\
\hline C6 & 6mo CD4/CD8 & CD4/CD8 ratio evaluated at 6 months postinfection \\
\hline C7 & $12 \mathrm{mo} C D 4$ & Absolute $\mathrm{CD} 4^{+} \mathrm{T}$-cell count evaluated at 12 months postinfection \\
\hline $\mathrm{C} 8$ & $12 \mathrm{mo} \% \mathrm{CD} 4$ & Percentage of $\mathrm{CD}^{+} \mathrm{T}$-cells evaluated at 12 months postinfection \\
\hline C9 & $12 \mathrm{mo} C D 4 / \mathrm{CD} 8$ & $\mathrm{CD} 4 / \mathrm{CD} 8$ ratio evaluated at 12 months postinfection \\
\hline $\mathrm{C} 10$ & CD4 Slope & $\begin{array}{l}\text { Rate of } \mathrm{CD} 4^{+} \mathrm{T} \text {-cell decay over the first year postinfection } \\
\text { (cells/ } \mu \mathrm{L} / \text { day) }\end{array}$ \\
\hline $\mathrm{C} 11$ & Baseline VL & Plasma viral load evaluated at enrollment (RNA copies/mL) \\
\hline $\mathrm{C} 12$ & Baseline $\log _{10} \mathrm{VL}$ & $\log _{10}$ plasma viral load evaluated at enrollment \\
\hline $\mathrm{C} 13$ & $6 \mathrm{mo} V L$ & $\begin{array}{l}\text { Plasma viral load evaluated at } 6 \text { months postinfection (RNA } \\
\text { copies } / \mathrm{mL} \text { ) }\end{array}$ \\
\hline $\mathrm{C} 14$ & $6 \mathrm{mo} \log _{10} \mathrm{VL}$ & $\log _{10}$ plasma viral load evaluated at 6 months postinfection \\
\hline C15 & $12 \mathrm{mo} \mathrm{VL}$ & $\begin{array}{l}\text { Plasma viral load evaluated at } 12 \text { months postinfection (RNA } \\
\text { copies } / \mathrm{mL} \text { ) }\end{array}$ \\
\hline $\mathrm{C} 16$ & $12 \mathrm{mo} \log _{10} \mathrm{VL}$ & $\log _{10}$ plasma viral load evaluated at 12 months postinfection \\
\hline IA1 & CD4CD38 & Percentage of $\mathrm{CD}^{+}{ }^{+} \mathrm{CD} 38^{+}$T-cells evaluated at enrollment \\
\hline IA2 & CD4HLADR & Percentage of $\mathrm{CD}^{+}{ }^{+} \mathrm{HLA}-\mathrm{DR}^{+}$T-cells evaluated at enrollment \\
\hline IA3 & CD4double & $\begin{array}{l}\text { Percentage of } \mathrm{CD}^{+}{ }^{+} \mathrm{CD} 38^{+} \mathrm{HLA}^{-\mathrm{DR}^{+}}{ }^{\mathrm{T}} \text {-cells evaluated at } \\
\text { enrollment }\end{array}$ \\
\hline IA4 & CD8CD38 & Percentage of $\mathrm{CD}^{+}{ }^{+} \mathrm{CD} 38^{+}$T-cells evaluated at enrollment \\
\hline IA5 & CD8HLADR & Percentage of $\mathrm{CD}^{+}{ }^{+} \mathrm{HLA}-\mathrm{DR}^{+}$T-cells evaluated at enrollment \\
\hline IA6 & CD8double & $\begin{array}{l}\text { Percentage of } \mathrm{CD}^{+}{ }^{+} \mathrm{CD} 38^{+} \mathrm{HLA}^{-\mathrm{DR}^{+}} \mathrm{T} \text {-cells evaluated at } \\
\text { enrollment }\end{array}$ \\
\hline
\end{tabular}


Table A1. Cont.

\begin{tabular}{|c|c|c|}
\hline Variable ID & Variable Name & Variable Description \\
\hline IR1 & $\%$ Nef response & $\begin{array}{l}\text { Percentage of T-cell response directed to Nef (over total } \\
\text { HIV-specific response) evaluated at enrollment by ELISPOT }\end{array}$ \\
\hline IR2 & $\begin{array}{l}\text { Absolute Nef } \\
\text { response }\end{array}$ & $\begin{array}{l}\text { Magnitude of Nef-specific response evaluated at enrollment by } \\
\text { ELISPOT (SFU/million PBMC) }\end{array}$ \\
\hline IR3 & $\%$ Gag response & $\begin{array}{l}\text { Percentage of T-cell response directed to Gag (over total } \\
\text { HIV-specific response) evaluated at enrollment by ELISPOT }\end{array}$ \\
\hline IR4 & $\begin{array}{l}\text { Absolute Gag } \\
\text { response }\end{array}$ & $\begin{array}{l}\text { Magnitude of Gag-specific response evaluated at enrollment by } \\
\text { ELISPOT (SFU/million PBMC) }\end{array}$ \\
\hline G1 & GS1 & $\begin{array}{l}\text { Additive genetic score constructed based on the presence or } \\
\text { absence of certain HLA alleles, as described previously [30]. } \\
\text { Alleles with a previous reported protective effect were added }(+1) \text {, } \\
\text { and risk alleles were subtracted (-1). Based on relevant } \\
\text { bibliography, HLA-A*02, HLA-A*32, HLA-A*68, HLA-B*15, } \\
\text { HLA-B*13, HLA-B*27, HLA-B*32, HLA-B*39, HLA-B*44, } \\
\text { HLA-B*51 and HLA-B*57 were considered as protective. } \\
\text { HLA-A } 11 \text {, HLA-A*23, HLA-A* } 24 \text {, HLA-B*08, HLA-B*35, } \\
\text { HLA-B*53, HLA-C*04 and HLA-C*07 were considered as } \\
\text { deleterious. Other HLA alleles were considered as neutral }(0) \text {. } \\
\text { Heterozygosis for HLA was considered as protective }(1) \text { and } \\
\text { homozygosis as deleterious }(-1) \text {. }\end{array}$ \\
\hline G2 & GS3 & $\begin{array}{l}\text { Additive genetic score constructed based on the presence or } \\
\text { absence of certain HLA alleles and CCR5 genotypes, as described } \\
\text { previously [30]. HLA alleles associated with protection or risk } \\
\text { were considered as in GS1. For CCR5 polymorphisms, } \Delta 32 \text { and } \\
\text { CCR2-64I alleles were considered as protective. CCR5 genotypes } \\
\text { HHC/HHF*2 and HHC/HHG*2 were considered as protective } \\
(+1), \mathrm{HHC} / \mathrm{HHE}, \mathrm{HHE} / \mathrm{HHE} \text { and HHE/HHG*2 were considered } \\
\text { as deleterious }(-1) \text {, and the others as neutral }(0) \text {. }\end{array}$ \\
\hline G3 & GS5 & $\begin{array}{l}\text { Additive genetic score constructed based on adding }+1 \text { when a } \\
\text { protective allele was present and subtracting }-1 \text { when a risk allele } \\
\text { was present. Protective and risk alleles were determined based on } \\
\text { the odd ratio obtained for each allele in our cohort with a } p<0.05 \text {. } \\
\text { HLA alleles with } p>0.05 \text { were considered as neutral }(0) \text {. }\end{array}$ \\
\hline G4 & GS6 & $\begin{array}{l}\text { Idem to GS5 but the cut-off level for significance was established } \\
\text { at } p<0.03 \text {. }\end{array}$ \\
\hline G5 & GS7 & $\begin{array}{l}\text { Constructed by multiplying the odds ratio corresponding to the } \\
6 \text {-month } \mathrm{CD} 4^{+} \mathrm{T} \text {-cell count for each of the } 6 \text { HLA alleles (A, B and } \\
\text { C) of each individual. }\end{array}$ \\
\hline G6 & GS8 & $\begin{array}{l}\text { Constructed by multiplying the odds ratio corresponding to the } \\
6 \text {-month VL for each of the } 6 \text { HLA alleles (A, B and C) of each } \\
\text { individual. }\end{array}$ \\
\hline G7 & GS9 & $\begin{array}{l}\text { Constructed by multiplying the odds ratio corresponding to the } \\
6 \text {-month } \mathrm{CD} 4^{+} \mathrm{T} \text {-cell count for each of the } 2 \text { CCR } 5 \text { haplotypes of } \\
\text { each individual. }\end{array}$ \\
\hline G8 & GS10 & $\begin{array}{l}\text { Constructed by multiplying the odds ratio corresponding to the } \\
6 \text {-month VL for each of the } 2 \text { CCR } 5 \text { haplotypes of each individual. }\end{array}$ \\
\hline G9 & GS11 & $\begin{array}{l}\text { Constructed by multiplying the odds ratio corresponding to the } \\
6 \text {-month CD } 4^{+} \text {T-cell count for each of the } 6 \text { HLA alleles (A, B and } \\
\text { C) and the } 2 \text { CCR5 haplotypes of each individual. }\end{array}$ \\
\hline
\end{tabular}


Table A1. Cont.

\begin{tabular}{|c|c|c|}
\hline Variable ID & Variable Name & Variable Description \\
\hline G10 & GS12 & $\begin{array}{l}\text { Constructed by multiplying the odds ratio corresponding to the } \\
6 \text {-month VL for each of the } 6 \text { HLA alleles (A, B and C) and the } 2 \\
\text { CCR5 haplotypes of each individual. }\end{array}$ \\
\hline PSF1 & EGF & $\begin{array}{l}\text { Plasma level of EGF (Endothelial growth factor) evaluated at } \\
\text { enrollment by Luminex }(\mathrm{pg} / \mathrm{mL})\end{array}$ \\
\hline PSF2 & Eotaxin & $\begin{array}{l}\text { Plasma level of Eotaxin evaluated at enrollment by Luminex } \\
(\mathrm{pg} / \mathrm{mL})\end{array}$ \\
\hline PSF3 & FGF2 & $\begin{array}{l}\text { Plasma level of FGF-2 (fibroblast growth factor } 2) \text { evaluated at } \\
\text { enrollment by Luminex }(\mathrm{pg} / \mathrm{mL})\end{array}$ \\
\hline PSF4 & Flt3Ligand & $\begin{array}{l}\text { Plasma level of Flt-3 (Fms-like tyrosine kinase } 3 \text { ) ligand evaluated } \\
\text { at enrollment by Luminex }(\mathrm{pg} / \mathrm{mL})\end{array}$ \\
\hline PSF5 & Fractalkine & $\begin{array}{l}\text { Plasma level of Fractalkine evaluated at enrollment by Luminex } \\
(\mathrm{pg} / \mathrm{mL})\end{array}$ \\
\hline PSF6 & GCSF & $\begin{array}{l}\text { Plasma level of G-CSF (granulocyte colony-stimulating factor) } \\
\text { evaluated at enrollment by Luminex (pg/mL) }\end{array}$ \\
\hline PSF7 & GMCSF & $\begin{array}{l}\text { Plasma level of GM-CSF (granulocyte monocyte } \\
\text { colony-stimulating factor) evaluated at enrollment by Luminex } \\
\text { (pg/mL) }\end{array}$ \\
\hline PSF8 & GRO & $\begin{array}{l}\text { Plasma level of GRO evaluated at enrollment by Luminex } \\
(\mathrm{pg} / \mathrm{mL})\end{array}$ \\
\hline PSF9 & IFN- $\alpha 2$ & $\begin{array}{l}\text { Plasma level of IFN- } \alpha 2 \text { (interferon alpha } 2) \text { evaluated at } \\
\text { enrollment by Luminex (pg/mL) }\end{array}$ \\
\hline PSF10 & IFN- $\gamma$ & $\begin{array}{l}\text { Plasma level of IFN- } \gamma \text { (interferon gamma) evaluated at enrollment } \\
\text { by Luminex }(\mathrm{pg} / \mathrm{mL})\end{array}$ \\
\hline PSF11 & $\operatorname{IL} 1 \alpha$ & $\begin{array}{l}\text { Plasma level of IL-1 } \alpha \text { (interleukin } 1 \text { alpha) evaluated at } \\
\text { enrollment by Luminex }(\mathrm{pg} / \mathrm{mL})\end{array}$ \\
\hline PSF12 & IL1 $\beta$ & $\begin{array}{l}\text { Plasma level of IL-1 } \beta \text { (interleukin } 1 \text { beta) evaluated at enrollment } \\
\text { by Luminex }(\mathrm{pg} / \mathrm{mL})\end{array}$ \\
\hline PSF13 & IL1ra & $\begin{array}{l}\text { Plasma level of IL-1ra (interleukin } 1 \text { receptor antagonist) } \\
\text { evaluated at enrollment by Luminex }(\mathrm{pg} / \mathrm{mL})\end{array}$ \\
\hline PSF14 & IL2 & $\begin{array}{l}\text { Plasma level of IL-2 (interleukin 2) evaluated at enrollment by } \\
\text { Luminex (pg/mL) }\end{array}$ \\
\hline PSF15 & IL3 & $\begin{array}{l}\text { Plasma level of IL-3 (interleukin 3) evaluated at enrollment by } \\
\text { Luminex (pg/mL) }\end{array}$ \\
\hline PSF16 & IL4 & $\begin{array}{l}\text { Plasma level of IL-4 (interleukin 4) evaluated at enrollment by } \\
\text { Luminex (pg/mL) }\end{array}$ \\
\hline PSF17 & IL5 & $\begin{array}{l}\text { Plasma level of IL-5 (interleukin 5) evaluated at enrollment by } \\
\text { Luminex (pg/mL) }\end{array}$ \\
\hline PSF18 & IL6 & $\begin{array}{l}\text { Plasma level of IL-6 (interleukin 6) evaluated at enrollment by } \\
\text { Luminex (pg/mL) }\end{array}$ \\
\hline PSF19 & IL7 & $\begin{array}{l}\text { Plasma level of IL-7 (interleukin 7) evaluated at enrollment by } \\
\text { Luminex (pg/mL) }\end{array}$ \\
\hline PSF20 & IL8 & $\begin{array}{l}\text { Plasma level of IL-8 (interleukin } 8 \text { ) evaluated at enrollment by } \\
\text { Luminex (pg/mL) }\end{array}$ \\
\hline PSF21 & IL9 & $\begin{array}{l}\text { Plasma level of IL-9 (interleukin 9) evaluated at enrollment by } \\
\text { Luminex (pg/mL) }\end{array}$ \\
\hline
\end{tabular}


Table A1. Cont.

\begin{tabular}{|c|c|c|}
\hline Variable ID & Variable Name & Variable Description \\
\hline PSF22 & IL10 & $\begin{array}{l}\text { Plasma level of IL-10 (interleukin 10) evaluated at enrollment by } \\
\text { Luminex }(\mathrm{pg} / \mathrm{mL})\end{array}$ \\
\hline PSF23 & IL12p40 & $\begin{array}{l}\text { Plasma level of IL-12p40 (interleukin } 12 \text { subunit } \mathrm{p} 40 \text { ) evaluated at } \\
\text { enrollment by Luminex (pg/mL) }\end{array}$ \\
\hline PSF24 & IL12p70 & $\begin{array}{l}\text { Plasma level of IL-12p70 (interleukin 12) evaluated at enrollment } \\
\text { by Luminex }(\mathrm{pg} / \mathrm{mL})\end{array}$ \\
\hline PSF25 & IL13 & $\begin{array}{l}\text { Plasma level of IL-13 (interleukin 13) evaluated at enrollment by } \\
\text { Luminex (pg/mL) }\end{array}$ \\
\hline PSF26 & IL15 & $\begin{array}{l}\text { Plasma level of IL-15 (interleukin 15) evaluated at enrollment by } \\
\text { Luminex (pg/mL) }\end{array}$ \\
\hline PSF27 & IL17 & $\begin{array}{l}\text { Plasma level of IL-17 (interleukin 17) evaluated at enrollment by } \\
\text { Luminex (pg/mL) }\end{array}$ \\
\hline PSF28 & IP10 & $\begin{array}{l}\text { Plasma level of IP10 (interferon gamma-induced protein 10, } \\
\text { CXCL10) evaluated at enrollment by Luminex }(\mathrm{pg} / \mathrm{mL})\end{array}$ \\
\hline PSF29 & $\mathrm{MCP1}$ & $\begin{array}{l}\text { Plasma level of MCP1 (monocyte chemoattractant protein } 1) \\
\text { evaluated at enrollment by Luminex }(\mathrm{pg} / \mathrm{mL})\end{array}$ \\
\hline PSF30 & $\mathrm{MCP} 3$ & $\begin{array}{l}\text { Plasma level of MCP3 (monocyte chemoattractant protein } 3) \\
\text { evaluated at enrollment by Luminex }(\mathrm{pg} / \mathrm{mL})\end{array}$ \\
\hline PSF31 & MDC & $\begin{array}{l}\text { Plasma level of MDC (macrophage derived chemokine, CCL22) } \\
\text { evaluated at enrollment by Luminex }(\mathrm{pg} / \mathrm{mL})\end{array}$ \\
\hline PSF32 & $\mathrm{MIP} 1 \alpha$ & $\begin{array}{l}\text { Plasma level of MIP- } 1 \alpha \text { (macrophage inflammatory protein } 1 \\
\text { alpha) evaluated at enrollment by Luminex }(\mathrm{pg} / \mathrm{mL})\end{array}$ \\
\hline PSF33 & MIP1 $\beta$ & $\begin{array}{l}\text { Plasma level of MIP-1 } \beta \text { (macrophage inflammatory protein } 1 \text { beta) } \\
\text { evaluated at enrollment by Luminex }(\mathrm{pg} / \mathrm{mL})\end{array}$ \\
\hline PSF34 & sCD40L & $\begin{array}{l}\text { Plasma level of sCD40L (soluble CD40 ligand) evaluated at } \\
\text { enrollment by Luminex (pg/mL) }\end{array}$ \\
\hline PSF35 & $\operatorname{sIL} 2 R \alpha$ & $\begin{array}{l}\text { Plasma level of sIL-2R } \alpha \text { (soluble interleukin } 2 \text { receptor alpha) } \\
\text { evaluated at enrollment by Luminex }(\mathrm{pg} / \mathrm{mL})\end{array}$ \\
\hline PSF36 & TGF $\alpha$ & $\begin{array}{l}\text { Plasma level of TGF- } \alpha \text { (tumor growth factor alpha) evaluated at } \\
\text { enrollment by Luminex (pg/mL) }\end{array}$ \\
\hline PSF37 & $\mathrm{TNF} \alpha$ & $\begin{array}{l}\text { Plasma level of TNF- } \alpha \text { (tumor necrosis factor alpha) evaluated at } \\
\text { enrollment by Luminex }(\mathrm{pg} / \mathrm{mL})\end{array}$ \\
\hline PSF38 & $\mathrm{TNF} \beta$ & $\begin{array}{l}\text { Plasma level of TNF- } \beta \text { (tumor necrosis factor beta) evaluated at } \\
\text { enrollment by Luminex }(\mathrm{pg} / \mathrm{mL})\end{array}$ \\
\hline PSF39 & VEGF & $\begin{array}{l}\text { Plasma level of VEGF (vascular endothelial growth factor) } \\
\text { evaluated at enrollment by Luminex (pg/mL) }\end{array}$ \\
\hline PSF40 & LPS & $\begin{array}{l}\text { Plasma level of LPS (lipopolysaccharide) evaluated at enrollment } \\
\text { by Lal assay (EU/mL) }\end{array}$ \\
\hline PSF41 & CSVL1 & $\begin{array}{l}\text { Cytokines that significantly correlated with baseline VL were } \\
\text { considered (sIL-2R } \alpha \text {, TNF- } \alpha \text {, IP-10 and IL-10) to construct an } \\
\text { additive score based on } 1 \text { s and }-1 \text { s. If the cytokine value of the } \\
\text { subject was above } 75 \% \text { IQR corresponding to the group of healthy } \\
\text { donors (HD), then this cytokine was assigned a value of } 1 \text {. If the } \\
\text { value was below } 25 \% \text { IQR corresponding to HD, it was assigned a } \\
\text { value of }-1 \text {. If the value was within the range IQR } 25-75 \% \\
\text { corresponding to HD, it was assigned a value of } 0 \text {. }\end{array}$ \\
\hline
\end{tabular}


Table A1. Cont.

\begin{tabular}{|c|c|c|}
\hline Variable ID & Variable Name & Variable Description \\
\hline PSF42 & CSCD41 & $\begin{array}{l}\text { Cytokines that significantly correlated with baseline CD } 4^{+} \text {T-cell } \\
\text { counts were considered (sIL-2R } \alpha, \text { IP-10 and G-CSF) to construct } \\
\text { an additive score based on } 1 \text { s and }-1 \text { s. If the cytokine value of the } \\
\text { subject was above } 75 \% \text { IQR corresponding to the group of healthy } \\
\text { donors (HD), then this cytokine was assigned a value of }-1 \text {. If the } \\
\text { value was below } 25 \% \text { IQR corresponding to HD, it was assigned a } \\
\text { value of } 1 \text {. If the value was within the range IQR } 25-75 \% \\
\text { corresponding to HD, it was assigned a value of } 0 \text {. }\end{array}$ \\
\hline PSF43 & CST1 & Score defined as the arithmetic sum of CSVL1 + CSCD41. \\
\hline PSF44 & CSVL2 & $\begin{array}{l}\text { Cytokines that significantly correlated with baseline VL were } \\
\text { considered (sIL-2R } \alpha \text {, TNF- } \alpha, \text { IP-10 and IL-10) to construct an } \\
\text { additive score based on adding the corresponding Spearman's R } \\
\text { values. If the cytokine value of the subject was above } 75 \% \text { IQR } \\
\text { corresponding to the group of healthy donors (HD), then the } \\
\text { Spearman's R value corresponding to that cytokine was added to } \\
\text { the score. If the value was below } 25 \% \text { IQR corresponding to HD, } \\
\text { the Spearman's R value corresponding to that cytokine was } \\
\text { subtracted from the score. If the value was within the range } \\
\text { IQR } 25-75 \% \text { corresponding to HD, it was assigned a value of } 0 \text {. }\end{array}$ \\
\hline PSF45 & CSCD42 & $\begin{array}{l}\text { Cytokines that significantly correlated with baseline CD } 4^{+} \text {T-cell } \\
\text { counts were considered (sIL-2R } \alpha \text {, IP- } 10 \text { and G-CSF) to construct } \\
\text { an additive score based on adding the corresponding Spearman's } \\
\mathrm{R} \text { values. If the cytokine value of the subject was above } 75 \% \text { IQR } \\
\text { corresponding to the group of healthy donors (HD), then the } \\
\text { Spearman's R value corresponding to that cytokine was } \\
\text { subtracted from the score. If the value was below } 25 \% \text { IQR } \\
\text { corresponding to HD, the Spearman's R value corresponding to } \\
\text { that cytokine was added to the score. If the value was within the } \\
\text { range IQR } 25-75 \% \text { corresponding to HD, it was assigned a value of } \\
0 .\end{array}$ \\
\hline PSF46 & CST2 & Score defined as the arithmetic sum of CSVL2 + CSCD42 \\
\hline PSF47 & CSVL3 & $\begin{array}{l}\text { Cytokines that significantly correlated with baseline VL were } \\
\text { considered (sIL-2R } \alpha, \text { TNF- } \alpha, \text { IP- } 10 \text { and IL-10) to construct an } \\
\text { additive score based on normalizing the value of each of these } \\
\text { cytokines over the cytokine median of the PHI group and } \\
\text { multiplying this adjusted value by the corresponding Spearman's } \\
\text { R. }\end{array}$ \\
\hline PSF48 & CSCD43 & $\begin{array}{l}\text { Cytokines that significantly correlated with baseline CD } 4^{+} \text {T-cell } \\
\text { counts were considered (sIL-2R } \alpha, \mathrm{IP}-10 \text { and G-CSF) to construct } \\
\text { an additive score based on normalizing the value of each of these } \\
\text { cytokines over the cytokine median of the PHI group and } \\
\text { multiplying this adjusted value by the corresponding Spearman's } \\
\text { R. }\end{array}$ \\
\hline PSF49 & CST3 & Score defined as the arithmetic sum of CSVL3 + CSCD43. \\
\hline PSF50 & CSVL4 & $\begin{array}{l}\text { Cytokines that significantly correlated with baseline VL were } \\
\text { considered (sIL-2R } \alpha \text {, TNF- } \alpha \text {, IP- } 10 \text { and IL-10) to construct an } \\
\text { additive score based on multiplying the } \log _{10} \text { value of each of } \\
\text { these cytokines by the corresponding Spearman's R. }\end{array}$ \\
\hline PSF51 & CSCD44 & $\begin{array}{l}\text { Cytokines that significantly correlated with baseline } \mathrm{CD} 4^{+} \text {T-cell } \\
\text { counts were considered (sIL-2R } \alpha \text {, IP- } 10 \text { and G-CSF) to construct } \\
\text { an additive score based on normalizing the } \log _{10} \text { value of each of } \\
\text { these cytokines by the corresponding Spearman's R }\end{array}$ \\
\hline PSF52 & CST4 & It was defined as the arithmetic sum of CSVL $4+$ CSCD 44 \\
\hline
\end{tabular}




\section{References}

1. Maartens, G.; Celum, C.; Lewin, S.R. HIV infection: Epidemiology, pathogenesis, treatment, and prevention. Lancet 2014, 384, 258-271. [CrossRef]

2. Rutstein, S.E.; Ananworanich, J.; Fidler, S.; Johnson, C.; Sanders, E.J.; Sued, O.; Saez-Cirion, A.; Pilcher, C.D.; Fraser, C.; Cohen, M.S.; et al. Clinical and public health implications of acute and early HIV detection and treatment: A scoping review. J. Int. AIDS Soc. 2017, 20, 21579. [CrossRef] [PubMed]

3. McDermott, A.B.; Koup, R.A. CD8 $\left(^{+}\right)$T cells in preventing HIV infection and disease. Aids 2012, 26, 1281-1292. [CrossRef] [PubMed]

4. Burger, S.; Poles, M.A. Natural history and pathogenesis of human immunodeficiency virus infection. Semin. Liver Dis. 2003, 23, 115-124. [PubMed]

5. Mayeux, R. Biomarkers: Potential uses and limitations. NeuroRx J. Am. Soc. Exp. NeuroTher. 2004, 1, $182-188$. [CrossRef] [PubMed]

6. De Wit, S.; Battegay, M.; D’Arminio Monforte, A.; Lundgren, J.D.; Oprea, C.; Antinori, A.; Bhagani, S.; Fätkenheuer, G.; Friis-Moller, N.; Furrer, H.; et al. European AIDS Clinical Society; EACS: Brussels, Belgium, 2017.

7. Panel on Antiretroviral Guidelines for Adults and Adolescents. Guidelines for the Use of Antiretroviral Agents in HIV-1-Infected Adults and Adolescents; Department of Health and Human Services: Washington, DC, USA, 2015.

8. IAS-USA. Antiretroviral Treatment of Adult HIV Infection: 2014 Recommendations of the International Antiviral Society-USA Panel; IAS-USA: San Francisco, CA, USA, 2014.

9. WHO. Consolidated Guidelines on the Use of Antiretroviral Drugs for Treating and Preventing HIV Infection: Recommendations for a Public Health Approach, 2nd ed.; World Health Organization: Geneva, Switzerland, 2016.

10. Younesi, E.; Toldo, L.; Muller, B.; Friedrich, C.M.; Novac, N.; Scheer, A.; Hofmann-Apitius, M.; Fluck, J. Mining biomarker information in biomedical literature. BMC Med. Inform. Decis. Mak. 2012, 12, 148. [CrossRef] [PubMed]

11. Williams, J.P.; Hurst, J.; Stohr, W.; Robinson, N.; Brown, H.; Fisher, M.; Kinloch, S.; Cooper, D.; Schechter, M.; Tambussi, G.; et al. HIV-1 DNA predicts disease progression and post-treatment virological control. eLife 2014, 3, e03821. [CrossRef] [PubMed]

12. Mahnke, Y.D.; Song, K.; Sauer, M.M.; Nason, M.C.; Giret, M.T.; Carvalho, K.I.; Costa, P.R.; Roederer, M.; Kallas, E.G. Early immunologic and virologic predictors of clinical HIV-1 disease progression. Aids 2013, 27, 697-706. [CrossRef] [PubMed]

13. Deeks, S.G.; Kitchen, C.M.; Liu, L.; Guo, H.; Gascon, R.; Narvaez, A.B.; Hunt, P.; Martin, J.N.; Kahn, J.O.; Levy, J.; et al. Immune activation set point during early HIV infection predicts subsequent CD4 ${ }^{+}$T-cell changes independent of viral load. Blood 2004, 104, 942-947. [CrossRef] [PubMed]

14. Deeks, S.G.; Tracy, R.; Douek, D.C. Systemic effects of inflammation on health during chronic HIV infection. Immunity 2013, 39, 633-645. [CrossRef] [PubMed]

15. Roberts, L.; Passmore, J.A.; Williamson, C.; Little, F.; Bebell, L.M.; Mlisana, K.; Burgers, W.A.; van Loggerenberg, F.; Walzl, G.; Djoba Siawaya, J.F.; et al. Plasma cytokine levels during acute HIV-1 infection predict HIV disease progression. Aids 2010, 24, 819-831. [CrossRef] [PubMed]

16. Liovat, A.S.; Rey-Cuille, M.A.; Lecuroux, C.; Jacquelin, B.; Girault, I.; Petitjean, G.; Zitoun, Y.; Venet, A.; Barre-Sinoussi, F.; Lebon, P.; et al. Acute plasma biomarkers of T cell activation set-point levels and of disease progression in HIV-1 infection. PLoS ONE 2012, 7, e46143. [CrossRef] [PubMed]

17. Keating, S.M.; Golub, E.T.; Nowicki, M.; Young, M.; Anastos, K.; Crystal, H.; Cohen, M.H.; Zhang, J.; Greenblatt, R.M.; Desai, S.; et al. The effect of HIV infection and HAART on inflammatory biomarkers in a population-based cohort of women. Aids 2011, 25, 1823-1832. [CrossRef] [PubMed]

18. Katsikis, P.D.; Mueller, Y.M.; Villinger, F. The cytokine network of acute HIV infection: A promising target for vaccines and therapy to reduce viral set-point? PLoS Pathog. 2011, 7, e1002055. [CrossRef] [PubMed]

19. Zuniga, R.; Lucchetti, A.; Galvan, P.; Sanchez, S.; Sanchez, C.; Hernandez, A.; Sanchez, H.; Frahm, N.; Linde, C.H.; Hewitt, H.S.; et al. Relative dominance of Gag p24-specific cytotoxic T lymphocytes is associated with human immunodeficiency virus control. J. Virol. 2006, 80, 3122-3125. [CrossRef] [PubMed]

20. Geldmacher, C.; Currier, J.R.; Herrmann, E.; Haule, A.; Kuta, E.; McCutchan, F.; Njovu, L.; Geis, S.; Hoffmann, O.; Maboko, L.; et al. CD8 T-cell recognition of multiple epitopes within specific Gag regions is associated with maintenance of a low steady-state viremia in human immunodeficiency virus type 1-seropositive patients. J. Virol. 2007, 81, 2440-2448. [CrossRef] [PubMed] 
21. Kiepiela, P.; Ngumbela, K.; Thobakgale, C.; Ramduth, D.; Honeyborne, I.; Moodley, E.; Reddy, S.; de Pierres, C.; Mncube, Z.; Mkhwanazi, N.; et al. CD8 ${ }^{+}$T-cell responses to different HIV proteins have discordant associations with viral load. Nat. Med. 2007, 13, 46-53. [CrossRef] [PubMed]

22. Streeck, H.; Jolin, J.S.; Qi, Y.; Yassine-Diab, B.; Johnson, R.C.; Kwon, D.S.; Addo, M.M.; Brumme, C.; Routy, J.P.; Little, S.; et al. Human immunodeficiency virus type 1-specific CD8 ${ }^{+}$T-cell responses during primary infection are major determinants of the viral set point and loss of CD4 ${ }^{+} \mathrm{T}$ cells. J. Virol. 2009, 83, 7641-7648. [CrossRef] [PubMed]

23. Masemola, A.; Mashishi, T.; Khoury, G.; Mohube, P.; Mokgotho, P.; Vardas, E.; Colvin, M.; Zijenah, L.; Katzenstein, D.; Musonda, R.; et al. Hierarchical targeting of subtype C human immunodeficiency virus type 1 proteins by CD8 ${ }^{+} \mathrm{T}$ cells: Correlation with viral load. J. Virol. 2004, 78, 3233-3243. [CrossRef] [PubMed]

24. Radebe, M.; Nair, K.; Chonco, F.; Bishop, K.; Wright, J.K.; van der Stok, M.; Bassett, I.V.; Mncube, Z.; Altfeld, M.; Walker, B.D.; et al. Limited immunogenicity of HIV CD8 ${ }^{+}$T-cell epitopes in acute Clade $\mathrm{C}$ virus infection. J. Infect. Dis. 2011, 204, 768-776. [CrossRef] [PubMed]

25. Ferrando-Martinez, S.; Casazza, J.P.; Leal, M.; Machmach, K.; Munoz-Fernandez, M.A.; Viciana, P.; Koup, R.A.; Ruiz-Mateos, E. Differential Gag-specific polyfunctional T cell maturation patterns in HIV-1 elite controllers. J. Virol. 2012, 86, 3667-3674. [CrossRef] [PubMed]

26. Naranbhai, V.; Carrington, M. Host genetic variation and HIV disease: From mapping to mechanism. Immunogenetics 2017, 69, 489-498. [CrossRef] [PubMed]

27. Socias, M.E.; Sued, O.; Laufer, N.; Lazaro, M.E.; Mingrone, H.; Pryluka, D.; Remondegui, C.; Figueroa, M.I.; Cesar, C.; Gun, A.; et al. Acute retroviral syndrome and high baseline viral load are predictors of rapid HIV progression among untreated Argentinean seroconverters. J. Int. AIDS Soc. 2011, 14, 40. [CrossRef] [PubMed]

28. Turk, G.; Ghiglione, Y.; Falivene, J.; Socias, M.E.; Laufer, N.; Coloccini, R.S.; Rodriguez, A.M.; Ruiz, M.J.; Pando, M.A.; Giavedoni, L.D.; et al. Early Gag immunodominance of the HIV-specific T-cell response during acute/early infection is associated with higher $\mathrm{CD} 8^{+} \mathrm{T}$-cell antiviral activity and correlates with preservation of the CD4 ${ }^{+}$T-cell compartment. J. Virol. 2013, 87, 7445-7462. [CrossRef] [PubMed]

29. Ghiglione, Y.; Falivene, J.; Ruiz, M.J.; Laufer, N.; Socias, M.E.; Cahn, P.; Giavedoni, L.; Sued, O.; Gherardi, M.M.; Salomon, H.; et al. Early skewed distribution of total and HIV-specific CD8 ${ }^{+}$T-cell memory phenotypes during primary HIV infection is related to reduced antiviral activity and faster disease progression. PLoS ONE 2014, 9, e104235. [CrossRef] [PubMed]

30. Coloccini, R.S.; Dilernia, D.; Ghiglione, Y.; Turk, G.; Laufer, N.; Rubio, A.; Socias, M.E.; Figueroa, M.I.; Sued, O.; Cahn, P.; et al. Host genetic factors associated with symptomatic primary HIV infection and disease progression among Argentinean seroconverters. PLoS ONE 2014, 9, e113146. [CrossRef] [PubMed]

31. Falivene, J.; Ghiglione, Y.; Laufer, N.; Socias, M.E.; Holgado, M.P.; Ruiz, M.J.; Maeto, C.; Figueroa, M.I.; Giavedoni, L.D.; Cahn, P.; et al. Th17 and Th17/Treg ratio at early HIV infection associate with protective HIV-specific CD8 $\left(^{+}\right)$T-cell responses and disease progression. Sci. Rep. 2015, 5, 11511. [CrossRef] [PubMed]

32. Thompson, M.A.; Aberg, J.A.; Hoy, J.F.; Telenti, A.; Benson, C.; Cahn, P.; Eron, J.J.; Gunthard, H.F.; Hammer, S.M.; Reiss, P.; et al. Antiretroviral treatment of adult HIV infection: 2012 recommendations of the International Antiviral Society-USA panel. JAMA 2012, 308, 387-402. [CrossRef] [PubMed]

33. Sociedad Argentina de Infectología (SADI). $V$ Consenso Argentino de Terapia Antirretroviral; SADI: Buenos Aires, Argentina, 2014; p. 200.

34. Turk, G.; Gherardi, M.M.; Laufer, N.; Saracco, M.; Luzzi, R.; Cox, J.H.; Cahn, P.; Salomon, H. Magnitude, breadth, and functional profile of T-cell responses during human immunodeficiency virus primary infection with B and BF viral variants. J. Virol. 2008, 82, 2853-2866. [CrossRef] [PubMed]

35. Giavedoni, L.D. Simultaneous detection of multiple cytokines and chemokines from nonhuman primates using luminex technology. J. Immunol. Methods 2005, 301, 89-101. [CrossRef] [PubMed]

36. Ruiz, M.J.; Ghiglione, Y.; Falivene, J.; Laufer, N.; Holgado, M.P.; Socias, M.E.; Cahn, P.; Sued, O.; Giavedoni, L.; Salomon, H.; et al. Env-Specific IgA from Viremic HIV-Infected Subjects Compromises Antibody-Dependent Cellular Cytotoxicity. J. Virol. 2016, 90, 670-681. [CrossRef] [PubMed]

37. Frank, E.; Hall, M.A.; Witten, I.H. The WEKA Workbench. In Online Appendix for "Data Mining: Practical Machine Learning Tools and Techniques", 4th ed.; Morgan Kauffmann Publishers Inc.: San Francisco, CA, USA, 2016.

38. Cohen, J. A Coefficient of Agreement for Nominal Scales. Educ. Psychol. Meas. 1960, 20, 37-46. [CrossRef] 
39. Huang, X.; Liu, X.; Meyers, K.; Liu, L.; Su, B.; Wang, P.; Li, Z.; Li, L.; Zhang, T.; Li, N.; et al. Cytokine cascade and networks among MSM HIV seroconverters: Implications for early immunotherapy. Sci. Rep. 2016, 6, 36234. [CrossRef] [PubMed]

40. McMichael, A.J.; Borrow, P.; Tomaras, G.D.; Goonetilleke, N.; Haynes, B.F. The immune response during acute HIV-1 infection: Clues for vaccine development. Nat. Rev. Immunol. 2010, 10, 11-23. [CrossRef] [PubMed]

41. Gay, C.; Dibben, O.; Anderson, J.A.; Stacey, A.; Mayo, A.J.; Norris, P.J.; Kuruc, J.D.; Salazar-Gonzalez, J.F.; Li, H.; Keele, B.F.; et al. Cross-sectional detection of acute HIV infection: Timing of transmission, inflammation and antiretroviral therapy. PLoS ONE 2011, 6, e19617. [CrossRef] [PubMed]

42. Brenchley, J.M.; Price, D.A.; Schacker, T.W.; Asher, T.E.; Silvestri, G.; Rao, S.; Kazzaz, Z.; Bornstein, E.; Lambotte, O.; Altmann, D.; et al. Microbial translocation is a cause of systemic immune activation in chronic HIV infection. Nat. Med. 2006, 12, 1365-1371. [CrossRef] [PubMed]

43. Catalfamo, M.; Le Saout, C.; Lane, H.C. The role of cytokines in the pathogenesis and treatment of HIV infection. Cytokine Growth Factor Rev. 2012, 23, 207-214. [CrossRef] [PubMed]

44. Stacey, A.R.; Norris, P.J.; Qin, L.; Haygreen, E.A.; Taylor, E.; Heitman, J.; Lebedeva, M.; DeCamp, A.; Li, D.; Grove, D.; et al. Induction of a striking systemic cytokine cascade prior to peak viremia in acute human immunodeficiency virus type 1 infection, in contrast to more modest and delayed responses in acute hepatitis B and C virus infections. J. Virol. 2009, 83, 3719-3733. [CrossRef] [PubMed]

45. Mueller, Y.M.; Katsikis, P.D. IL-15 in HIV infection: Pathogenic or therapeutic potential? Eur. Cytokine Netw. 2010, 21, 219-221. [PubMed]

46. Noel, N.; Boufassa, F.; Lecuroux, C.; Saez-Cirion, A.; Bourgeois, C.; Dunyach-Remy, C.; Goujard, C.; Rouzioux, C.; Meyer, L.; Pancino, G.; et al. Elevated IP10 levels are associated with immune activation and low CD4 $\left({ }^{+}\right)$T-cell counts in HIV controller patients. Aids 2014, 28, 467-476. [CrossRef] [PubMed]

47. Gray, C.M.; Hong, H.A.; Young, K.; Lewis, D.A.; Fallows, D.; Manca, C.; Kaplan, G. Plasma interferon-gamma-inducible protein 10 can be used to predict viral load in HIV-1-infected individuals. J. Acquir. Immune Defic. Syndr. 2013, 63, e115-e116. [CrossRef] [PubMed]

48. Kamat, A.; Misra, V.; Cassol, E.; Ancuta, P.; Yan, Z.; Li, C.; Morgello, S.; Gabuzda, D. A plasma biomarker signature of immune activation in HIV patients on antiretroviral therapy. PLoS ONE 2012, 7, e30881. [CrossRef] [PubMed]

49. Malherbe, G.; Steel, H.C.; Cassol, S.; de Oliveira, T.; Seebregts, C.J.; Anderson, R.; Cassol, E.; Rossouw, T.M. Circulating biomarkers of immune activation distinguish viral suppression from nonsuppression in HAART-treated patients with advanced HIV-1 subtype C infection. Mediat. Inflamm. 2014, 2014, 198413. [CrossRef] [PubMed]

50. Norris, P.J.; Zhang, J.; Worlock, A.; Nair, S.V.; Anastos, K.; Minkoff, H.L.; Villacres, M.C.; Young, M.; Greenblatt, R.M.; Desai, S.; et al. Systemic Cytokine Levels Do Not Predict CD4 $\left(^{+}\right)$T-Cell Recovery After Suppressive Combination Antiretroviral Therapy in Chronic Human Immunodeficiency Virus Infection. Open Forum Infect. Dis. 2016, 3, ofw025. [CrossRef] [PubMed]

51. Stiksrud, B.; Lorvik, K.B.; Kvale, D.; Mollnes, T.E.; Ueland, P.M.; Troseid, M.; Tasken, K.; Dyrhol-Riise, A.M. Plasma IP-10 Is Increased in Immunological NonResponders and Associated With Activated Regulatory T Cells and Persisting Low CD4 Counts. J. Acquir. Immune Defic. Syndr. 2016, 73, 138-148. [CrossRef] [PubMed]

52. Jiao, Y.; Zhang, T.; Wang, R.; Zhang, H.; Huang, X.; Yin, J.; Zhang, L.; Xu, X.; Wu, H. Plasma IP-10 is associated with rapid disease progression in early HIV-1 infection. Viral Immunol. 2012, 25, 333-337. [CrossRef] [PubMed]

53. Boyle, D.S.; Hawkins, K.R.; Steele, M.S.; Singhal, M.; Cheng, X. Emerging technologies for point-of-care CD4 T-lymphocyte counting. Trends Biotechnol. 2012, 30, 45-54. [CrossRef] [PubMed]

54. Duro, R.; Rocha-Pereira, N.; Figueiredo, C.; Pineiro, C.; Caldas, C.; Serrao, R.; Sarmento, A. Routine CD4 monitoring in HIV patients with viral suppression: Is it really necessary? A Portuguese cohort. J. Microbiol. Immunol. Infect. 2017. [CrossRef] [PubMed]

55. Caniglia, E.C.; Cain, L.E.; Sabin, C.A.; Robins, J.M.; Logan, R.; Abgrall, S.; Mugavero, M.J.; Hernandez-Diaz, S.; Meyer, L.; Seng, R.; et al. Comparison of dynamic monitoring strategies based on CD4 cell counts in virally suppressed, HIV-positive individuals on combination antiretroviral therapy in high-income countries: A prospective, observational study. Lancet HIV 2017, 4, e251-e259. [CrossRef] 
56. Cori, A.; Pickles, M.; van Sighem, A.; Gras, L.; Bezemer, D.; Reiss, P.; Fraser, C. CD4 ${ }^{+}$cell dynamics in untreated HIV-1 infection: Overall rates, and effects of age, viral load, sex and calendar time. Aids 2015, 29, 2435-2446. [CrossRef] [PubMed]

57. Ananworanich, J.; Chomont, N.; Eller, L.A.; Kroon, E.; Tovanabutra, S.; Bose, M.; Nau, M.; Fletcher, J.L.K.; Tipsuk, S.; Vandergeeten, C.; et al. HIV DNA Set Point is Rapidly Established in Acute HIV Infection and Dramatically Reduced by Early ART. EBioMedicine 2016, 11, 68-72. [CrossRef] [PubMed]

58. Chomont, N.; El-Far, M.; Ancuta, P.; Trautmann, L.; Procopio, F.A.; Yassine-Diab, B.; Boucher, G.; Boulassel, M.R.; Ghattas, G.; Brenchley, J.M.; et al. HIV reservoir size and persistence are driven by T cell survival and homeostatic proliferation. Nat. Med. 2009, 15, 893-900. [CrossRef] [PubMed]

59. Vandergeeten, C.; Fromentin, R.; Chomont, N. The role of cytokines in the establishment, persistence and eradication of the HIV reservoir. Cytokine Growth Factor Rev. 2012, 23, 143-149. [CrossRef] [PubMed]

2018 by the authors. Licensee MDPI, Basel, Switzerland. This article is an open access article distributed under the terms and conditions of the Creative Commons Attribution (CC BY) license (http://creativecommons.org/licenses/by/4.0/). 